\title{
The inhibitory action of purple tea on in vivo starch digestion compared to other Camellia sinensis teas
}

\author{
Tamires Barlati Vieira da Silva ${ }^{\text {a }}$, Pâmela Alves Castilho ${ }^{\text {a }}$, Anacharis Babeto de Sá-Nakanishi ${ }^{\text {a,b,c }}$, \\ Flávio Augusto Vicente Seixas ${ }^{\mathrm{d}}$, Maria Inês Dias ${ }^{\mathrm{e}}$, Lillian Barros ${ }^{\mathrm{e}}$, Isabel C.F.R. Ferreira ${ }^{\mathrm{e}}$, \\ Adelar Bracht ${ }^{\mathrm{a}, \mathrm{b}, \mathrm{c}}$, Rosane Marina Peralta ${ }^{\mathrm{a}, \mathrm{b}, \mathrm{c}, \text { " }}$ \\ ${ }^{a}$ Post-Graduate Program in Food Sciences, State University of Maringa, 87015-900 Maringá, Paraná, Brazil \\ ${ }^{\mathrm{b}}$ Department of Biochemistry, State University of Maringá, 87015-900 Maringá, PR, Brazil \\ ${ }^{\mathrm{c}}$ Post-Graduate Program in Biochemistry, State University of Maringá, 87015-900 Maringá, PR, Brazil \\ d Department of Technology, and Post-graduate Program of Molecular and Cell Biology, State University of Maringá, 87015-900 Maringá, PR, Brazil \\ ${ }^{\text {e }}$ Centro de Investigação da Montanha (CIMO), Instituto Politécnico de Bragança, Campus de Santa Apolónia, 5300-253 Bragança, Portugal
}

\section{A R T I C L E I N F O}

\section{Keywords:}

Amylase inhibitors

Starch digestion

Antiglycemic

Camellia sinensis

Purple tea

\begin{abstract}
A B S T R A C T
In order to contribute to improve knowledge about the actions of Camellia sinensis extracts on starch digestion, several varieties were compared. The latter were green, oolong, white, black, and purple teas. The results are hoped to contribute to our understanding of the mode of action and potency of the various tea preparations as possible adjuvants in the control of post-prandial glycemia. The extracts were prepared in way similar to their form of consumption. All extracts decreased starch digestion, but the purple tea extract was the strongest inhibitor, their inhibitory tendency started at the dose of $50 \mathrm{mg} / \mathrm{kg}$ and was already maximal with $250 \mathrm{mg} / \mathrm{kg}$. Maltose tolerance was not significantly affected by the extracts. Glucose tolerance was not affected by purple tea, but black tea clearly diminished it; green tea presented the same tendency. Purple tea was also the strongest inhibitor of pancreatic $\alpha$-amylase, followed by black tea. The green tea, oolong tea, and white tea extracts tended to stimulate the pancreatic $\alpha$-amylase at low concentrations, a phenomenon that could be counterbalancing its inhibitory effect on starch digestion. Based on chemical analyses and molecular docking simulations it was concluded that for both purple and black tea extracts the most abundant active component, epigallocatechin gallate, seems also to be the main responsible for the inhibition of the pancreatic $\alpha$-amylase and starch digestion. In the case of purple tea, the inhibitory activity is likely to be complemented by its content in deoxyhexosidehexoside-containing polyphenolics, especially the kaempferol and myricetin derivatives. Polysaccharides are also contributing to some extent. Cyanidins, the compounds giving to purple tea its characteristic color, seem not to be the main responsible for its effects on starch digestion. It can be concluded that in terms of postprandial anti-hyperglycemic action purple tea presents the best perspectives among all the tea varieties tested in the present study.
\end{abstract}

\section{Introduction}

Type 2 diabetes mellitus is the most common type of diabetes and its complications are a major global health problem (Wasana, Attanayake, Weerarathna, \& Jayatilaka, 2021). According to estimates of the 2019 International Diabetes Federation (IDF), there are around 460 million adults aged between 20 and 79 in the world suffering from diabetes (Saeedi et al., 2019). A frequent treatment for type 2 diabetes mellitus consists in the prescription of inhibitors of carbohydrate digestive enzymes aiming at reducing the absorption of monosaccharides originating from starch and sucrose (Awosika \& Aluko, 2019). Inhibition of starch digestion by ingesting $\alpha$-amylase and $\alpha$-glucosidase inhibitors is an especially effective way of diminishing post-prandial glycemia, but the drugs commonly used, such as acarbose, present several negative effects (Awosika \& Aluko, 2019; Gutiérrez-Grijalva, Antunes-Ricardo, Acosta-Estrada, Gutiérrez-Uribe, \& Basilio Heredia, 2019). For this reason, there has been continuous efforts at discovering natural antidiabetic agents that could provide mild anti-hyperglycemic protection

\footnotetext{
* Corresponding author at: Post-Graduate Program in Food Sciences, State University of Maringa, 87015-900 Maringá, Paraná, Brazil.

E-mail address: rmperalta@uem.br (R.M. Peralta).
} 
by virtue of a continuous ingestion in conjunction with the regular and daily food intake.

Infusions (teas) prepared with the various Camellia sinensis varieties have been suggested as potentially effective adjuvants in the protection against hyperglycemia episodes. The supporting evidence was derived mainly from in vitro measurements of the activities of $\alpha$-amylases (salivary and pancreatic) and yeast $\alpha$-glucosidase. Close analysis of the hitherto published results, however, reveals conflicting results. For example, it has been reported that a green tea extract inhibits the porcine pancreatic $\alpha$-amylase with a IC 50 of $4020 \mu \mathrm{g} / \mathrm{mL}$, but also that it inhibits the yeast $\alpha$-glucosidase with a $\mathrm{IC}_{50}$ of $4.4 \mu \mathrm{g} / \mathrm{mL}$ (Gao, Xu, Wang, Wang \& Hochstetter, 2013). The authors claim that the inhibitory activity of the green tea extract on the yeast $\alpha$-glucosidase enormously exceeds that of acarbose (the classical inhibitor of carbohydrate digestion), but the correct enzyme for comparisons should actually be the mammalian intestinal $\alpha$-glucosidase, which is very strongly inhibited by acarbose ( IC $_{50}=0.25 \mu \mathrm{g} / \mathrm{mL}$; (Zhang et al., 2017). In another study, a IC $_{50}$ of $2000 \mu \mathrm{g} / \mathrm{mL}$ for the inhibition of the human $\alpha$-amylase by a green tea extract was found (Miao, Jiang, Jiang, Zhang, \& Li, 2015). This would be similar to the value reported previously by porcine pancreatic $\alpha$-amylase inhibition. (Gao et al., 2013). However, Nyambe-Silavwe et al. (2015) claim that their green tea preparation inhibited the human salivary $\alpha$-amylase with a $\mathrm{IC}_{50}$ of $8.9 \mu \mathrm{g} / \mathrm{mL}$ when amylose was the substrate and of 25 to $69 \mu \mathrm{g} / \mathrm{mL}$ when amylopectin was the substrate, numbers that are not in agreement with those reported by Gao et al. (2013) and Miao et al.(2015). Yang and Kong (2016), on the other hand, reported biphasic effects for green, oolong and black tea extracts in addition to a polyphenolic preparation extracted from Camellia sinensis: stimulation at low concentrations, followed by inhibition at higher ones.

These and other contradicting reports (Yang et al., 2019) may have resulted from different assay conditions and preparations of the tea extracts. Contradictions, however, are of limited help when one tries to translate them to the in vivo situation. In vivo experiments are, thus, highly desirable at the present stage. There is one in vivo study in humans indicating that green tea may indeed affect carbohydrate digestion (Lochocka et al., 2015). In this study the influence of a green tea extract ( $4 \mathrm{~g}$ dose) was investigated on the ${ }^{13} \mathrm{CO}_{2}$ recovery in breath after the ingestion of ${ }^{13} \mathrm{C}$ labeled cornflakes. The study found a reduced ${ }^{13} \mathrm{CO}_{2}$ recovery in individuals who had ingested the green tea extract. This outcome was interpreted as representing inhibition of starch digestion caused mainly by the reported $\alpha$-glucosidase inhibition (Gao et al., 2013). This is no doubt a reasonable interpretation in view of the available evidence, but one should not forget that there is a long metabolic way between starch digestion and $\mathrm{CO}_{2}$ production, so that there are many other mechanistic alternatives. In this respect there is a more direct way of inferring about starch digestion, which consists in measuring the glycemic levels in animals just after a starch load. This technique has proven to be an adequate procedure for evaluating the action of starch digestion in the intestine (Kato-Schwartz et al., 2018, 2020). In order to contribute further for clarifying the effects of Camellia sinensis extracts on starch digestion, we are proposing in this work a comparative study of the effects of five varieties on starch digestion using the starch tolerance test in mice. The varieties to be investigated are green, oolong, white, black and purple tea. Emphasis will be given to purple tea, however, which represents a new and promising variety in terms of medicinal effects. The latter differs from the other tea varieties because of its unique purple leaves (Kerio, Wachira, Wanyoko, \& Rotich, 2012; Lai et al., 2016). The leaves have this color because they contain anthocyanins in quantities that largely exceed the contents of other tea varieties. Anthocyanins are claimed to possess many functional and biological properties (Adisakwattana, Yibchok-Anun, Charoenlertkul, \& Wongsasiripat, 2011; Kong, Chia, Goh, Chia \& Brouillard, 2003), including beneficial effects in diabetic individuals (Rocha et al., 2019), but the pharmacologic potential of purple tea is much less known than that of green tea, for example. In line with the present attempts at finding antidiabetic agents that will allow mild anti-hyperglycemic protection by virtue of its continuous ingestion in parallel with the regular food intake, the extracts used in the present study will be prepared in a way that simulates their preparation for regular consumption. It is hoped that the results will contribute significantly to our understanding of the mode of action and potency of the various tea preparations as possible adjuvants in the control of post-prandial glycemia.

\section{Material and methods}

\subsection{Material}

Porcine pancreatic $\alpha$-amylase (type IV-B), and potato starch were purchased from Sigma-Aldrich. Acarbose was obtained from local pharmacies. All reagent grade chemicals were from the highest possible degree of purity.

\subsection{Preparation of the aqueous tea extracts}

The commercial Camellia sinensis var. assamica products labeled as green tea, oolong tea, white tea, and black tea were purchased in the local market (Maringá, Brazil). Kenyan purple tea (purple tea) was purchased from Justea.com, Vancouver, Canada. Purple tea is a special type of tea produced mostly in Kenya. Differently from green, oolong, black, and white tea, purple tea is not a tea type characterized by its manufacturing, but a different cultivar called TRFK 306/1 (Kilel et al., 2013). It can be used for manufacturing all types of tea, but the sample used in the present study was manufactured followed the procedures used to prepare green tea.

The extracts were prepared according to the protocol described by Lochocka et al. (2015). The tea leaves (100 g) were ground, boiled in distilled water $(1000 \mathrm{~mL})$ and subsequently stirred for $15 \mathrm{~min}$ at $70{ }^{\circ} \mathrm{C}$ (repeated 3 times). The collected extracts were filtered, frozen and lyophilized under vacuum at $-20^{\circ} \mathrm{C}$.

\subsection{Analysis of phenolic compounds}

The lyophilized extracts were dissolved in methanol/water (80:20, $v / v$ ) to a final concentration of $10 \mathrm{mg} / \mathrm{mL}$ and filtered through $0.22 \mu \mathrm{m}$ disposable filter disks. Analysis was performed in a HPLC system (Dionex Ultimate 3000 UPLC, Thermo Scientific, San Jose, CA, USA) coupled to a diode-array detector (DAD, using 280 and $370 \mathrm{~nm}$ as preferred wavelengths) and a Linear Ion Trap (LTQ XL) mass spectrometer (MS, Thermo Finnigan, San Jose, CA, USA) equipped with an electrospray ionization (ESI) source. Separation was made in a Waters Spherisorb S3 ODS-2 C18 column ( $3 \mu \mathrm{m}, 4.6 \mathrm{~mm} \times 150 \mathrm{~mm}$; Waters, Milford, MA, USA). The operating conditions were previously described by Bessada, Barreira, Barros, Ferreira \& Oliveira (2016). The identification of phenolic compounds was achieved by comparing retention times, UV-Vis and mass spectra with available standard compounds. Otherwise, available data reported in the literature were applied to tentatively identify the compounds. Quantitative analysis was performed using a 7level calibration curves of each available phenolic standard constructed upon the UV signal: apigenin-6-C-glucoside $\left(y=107025 x+61531, R^{2}\right.$ $=0.9989 ; \mathrm{LOD}=0.19 \mu \mathrm{g} / \mathrm{mL} ; \mathrm{LOQ}=0.63 \mu \mathrm{g} / \mathrm{mL}) ;$ chlorogenic acid $(y$ $=168823 x-161172, R^{2}=0.9999 ; \mathrm{LOD}=0.20 \mu \mathrm{g} / \mathrm{mL} ; \mathrm{LOQ}=0.68 \mu \mathrm{g} /$ $\mathrm{mL})$; gallic acid $\left(y=131538 x+292163, R^{2}=0.9969 ; \mathrm{LOD}=0.28 \mu \mathrm{g} /\right.$ $\mathrm{mL} ; \mathrm{LOQ}=0.87 \mu \mathrm{g} / \mathrm{mL})$; B - catechin $\left(y=84950 x-23200, R^{2}=1\right.$; LOD $=0.17 \mu \mathrm{g} / \mathrm{mL} ; \mathrm{LOQ}=0.68 \mu \mathrm{g} / \mathrm{mL}) ;$ myricetin-3-O-glucoside $(y=$ $23287 x-581708, R^{2}=0.9988 ; \mathrm{LOD}=0.23 \mu \mathrm{g} / \mathrm{mL} ; \mathrm{LOQ}=0.78 \mu \mathrm{g} /$ $\mathrm{mL})$; and quercetin-3-O-glucoside $\left(y=34843 x-160173, R^{2}=0.9998\right.$; LOD $=0.21 \mu \mathrm{g} / \mathrm{mL}$; LOQ $=0.71 \mu \mathrm{g} / \mathrm{mL}$ ). For the Identified phenolic compounds with unavailable commercial standard these were quantified using the calibration curve of the most similar standard available. The analyses were carried out in triplicate and the results are expressed as mean values and standard deviations (SD), in $\mathrm{mg} / \mathrm{g}$ of lyophilized extract. 


\subsection{Total anthocyanin assay}

The total anthocyanin contents of the various tea extracts were evaluated by the $\mathrm{pH}$ differential method according to the $\mathrm{pH}$ differential method Lee et al. (2005). The pH 1.0 buffer was $0.025 \mathrm{M}$ hydrochloric acid-potassium chloride buffer $(\mathrm{HCl}-\mathrm{KCl})$ and the $\mathrm{pH} 4.5$ buffer was 0.4 $\mathrm{M}$ sodium acetate. The sample dilution was established by limiting the $\mathrm{pH} 1.0$ absorbance at $520 \mathrm{~nm}$ between 0.2 and 1.4. The total anthocyanin content of each sample $\left(\mathrm{C}_{\mathrm{TA}} ; \mathrm{mg}\right.$ cyanidin-3-O'-glucoside equivalents per $\mathrm{g}$ extract) was calculated by the following formula:

$C_{T A}=\frac{A \times m w \times D F \times 10^{3}}{\varepsilon \times \ell \times W}$

$A$ is the specific absorbance, $m w$ the molecular weight of cyanidin-3'-Oglucoside $(449.2 \mathrm{~g} / \mathrm{mol})$, DF the dilution factor, $\varepsilon$ the molar extinction coefficient of cyanidin-3'-O-glucoside at $520 \mathrm{~nm}\left(2.69 \times 10^{4} \mathrm{M}^{-1} \mathrm{~cm}^{-1}\right)$, $\ell$ the light path length $(\mathrm{cm}), W$ the amount that was extracted (in $\mathrm{mg} /$ $100 \mathrm{~g}$ dry weight) and $10^{3} \mathrm{a}$ factor for the conversion of $\mathrm{g}$ into $\mathrm{mg}$. The specific absorbance $\mathrm{A}$ is defined as:

$\mathrm{A}=\left(\mathrm{A}_{520 \mathrm{~nm}}-\mathrm{A}_{700 \mathrm{~nm}}\right)_{\mathrm{pH} 1.0}-\left(\mathrm{A}_{520 \mathrm{~nm}}-\mathrm{A}_{700 \mathrm{~nm}}\right)_{\mathrm{pH} 4.5}$

\subsection{Polysaccharide extraction}

High-molecular weight components (mainly polysaccharides) were precipitated by addition of 3 volumes of cold absolute ethanol to each aqueous extract (Deng et al., 2015). The mixtures were maintained at $8{ }^{\circ} \mathrm{C}$ overnight and separated by centrifugation $\left(8000 \mathrm{rpm}\right.$ at $4{ }^{\circ} \mathrm{C}, 30$ $\mathrm{min})$. The sediments were washed with ethanol twice and finally dissolved in water. These materials were called ethanol precipitated fractions (EP). Total sugars were assayed by the phenol-sulfuric method based on the absorbance at $490 \mathrm{~nm}$ of the phenol-carbohydrate complex (Dubois et al., 1956) and expressed as mg sugars/g extract. Glucose was used for constructing the standard curve.

\subsection{Pancreatic $\alpha$-amylase assay}

Initial reaction rates catalyzed by the porcine pancreatic $\alpha$-amylase were measured at $37{ }^{\circ} \mathrm{C}$ and $\mathrm{pH} 6.9$ in absence or presence of various tea extract concentrations (Kato et al., 2017). The $\mathrm{pH}$ used is close to the optimum reported previously (da Silva et al., 2014). The substrate was potato starch up to $1.0 \mathrm{~g}$ per $100 \mathrm{~mL}$ prepared in $20 \mathrm{mmol} / \mathrm{L}$ phosphate buffer plus $6.7 \mathrm{mmol} / \mathrm{L} \mathrm{NaCl}$. The amount of enzyme added to each reaction mixture was 1 unit (specific activity 500 units/mg protein). Two different protocols were used. In the first one, the substrate and one of the tea extracts or redissolved ethanol precipitates (at various concentrations) were incubated for $30 \mathrm{~min}$ at $37^{\circ} \mathrm{C}$ and the reaction was started by adding the enzyme. In the second protocol the enzyme and one of the tea extracts or redissolved ethanol precipitates (at various concentrations) were incubated for $30 \mathrm{~min}$ at $37^{\circ} \mathrm{C}$ and the reaction was initiated by the addition of substrate. These two protocols are justified by the observation that the degree of inhibition of the $\alpha$-amylase phenolic compounds is affected by the addition order of the reaction participants (D'Costa \& Bordenave, 2021). For both protocols the reaction was allowed to proceed for $10 \mathrm{~min}$. After this time the amount of reducing sugars in the reaction medium was quantified using the 3,5dinitrosalicylic acid procedure (Miller, 1959). The standard curve was constructed with maltose. No changes in $\mathrm{pH}$ were observed during the incubation time.

\subsection{Molecular docking}

The structures of the phenolic compounds identified in Table 1 were obtained from the PubChem database (Kim et al., 2016) in the *.sdf format. All possible variations for a pentoside or hexoside that were available in PubChem were considered in order to cope for eventual
Table 1

Tentative identification and quantification (mg/g of extract) of the phenolic compounds present in the extracts of the various tea varieties (Camellia sinensis) used in the present work. Full experimental details are given in the Section 2.

\begin{tabular}{|c|c|c|c|c|c|}
\hline $\begin{array}{l}\text { Tentative } \\
\text { identification }\end{array}$ & $\begin{array}{l}\text { Green } \\
\text { tea } \\
\mathrm{mg} / \mathrm{g} \\
\text { extract }\end{array}$ & $\begin{array}{l}\text { Purple } \\
\text { tea }\end{array}$ & $\begin{array}{l}\text { Oolong } \\
\text { tea }\end{array}$ & $\begin{array}{l}\text { White } \\
\text { tea }\end{array}$ & $\begin{array}{l}\text { Black } \\
\text { tea }\end{array}$ \\
\hline $\begin{array}{l}\text { (Epi)gallocatechin } \\
\text { isomer } \mathrm{I}^{\mathrm{A}}\end{array}$ & $\begin{array}{l}0.72 \pm \\
0.03\end{array}$ & $\begin{array}{l}5.67 \pm \\
0.07\end{array}$ & $\begin{array}{l}0.127 \pm \\
0.007\end{array}$ & - & - \\
\hline $\begin{array}{l}\text { (Epi)gallocatechin } \\
\text { isomer } \mathrm{II}^{\mathrm{A}}\end{array}$ & $\begin{array}{l}2.52 \pm \\
0.02\end{array}$ & - & $\begin{array}{l}0.49 \pm \\
0.01\end{array}$ & - & - \\
\hline $\begin{array}{l}\text { (Epi)gallocatechin } \\
\text { isomer } \mathrm{III}^{\mathrm{A}}\end{array}$ & $\begin{array}{l}2.12 \pm \\
0.08\end{array}$ & - & $\begin{array}{l}0.31 \pm \\
0.01\end{array}$ & - & - \\
\hline$(+)$-Catechin ${ }^{\mathrm{A}}$ & $\begin{array}{l}4.8 \pm \\
0.2\end{array}$ & $\begin{array}{l}1.76 \pm \\
0.01\end{array}$ & $\begin{array}{l}0.704 \pm \\
0.006\end{array}$ & $\begin{array}{l}0.082 \\
\pm 0.002\end{array}$ & $\begin{array}{l}1.25 \pm \\
0.03\end{array}$ \\
\hline $\begin{array}{l}\text { Epigallocatechin } \\
\text { gallate }^{\mathrm{A}}\end{array}$ & $\begin{array}{l}30.2 \pm \\
0.4\end{array}$ & $\begin{array}{l}11.6 \pm \\
0.1\end{array}$ & $\begin{array}{l}6.48 \pm \\
0.05^{*}\end{array}$ & $\begin{array}{l}6.24 \pm \\
0.08^{*}\end{array}$ & $\begin{array}{l}8.5 \pm \\
0.1\end{array}$ \\
\hline $\begin{array}{l}\text { 3-O-Caffeoylquinic } \\
\text { acid }^{\mathrm{B}}\end{array}$ & - & - & - & $\begin{array}{l}1.31 \pm \\
0.02\end{array}$ & - \\
\hline $\begin{array}{l}\text { 4-O-Caffeoylquinic } \\
\text { acid }^{\mathrm{B}}\end{array}$ & - & - & - & $\begin{array}{l}0.570 \\
\pm 0.001\end{array}$ & - \\
\hline $\begin{array}{l}\text { 5-O-Caffeoylquinic } \\
\text { acid }^{\mathrm{B}}\end{array}$ & - & - & - & $\begin{array}{l}1.06 \pm \\
0.02\end{array}$ & - \\
\hline Theasinensin $\mathrm{B}(\text { or } \mathrm{E})^{\mathrm{C}}$ & - & - & - & - & $\begin{array}{l}1.06 \pm \\
0.05\end{array}$ \\
\hline $\begin{array}{l}\text { Apigenin- } C \text {-hexoside- } \\
O \text {-pentoside }\end{array}$ & $\begin{array}{l}0.34 \pm \\
0.02\end{array}$ & $\begin{array}{l}0.046 \pm \\
0.001^{*}\end{array}$ & $\begin{array}{l}0.042 \pm \\
0.001^{*}\end{array}$ & $\begin{array}{l}0.061 \\
\pm \\
0.005^{*}\end{array}$ & $\begin{array}{l}0.031 \\
\pm \\
0.001 *\end{array}$ \\
\hline $\begin{array}{l}\text { Apigenin- } C \text {-hexoside- } \\
O \text {-pentoside }\end{array}$ & $\begin{array}{l}0.38 \pm \\
0.01\end{array}$ & $\begin{array}{l}0.028 \pm \\
0.001\end{array}$ & $\begin{array}{l}0.061 \pm \\
0.001\end{array}$ & $\begin{array}{l}0.074 \\
\pm 0.006\end{array}$ & $\begin{array}{l}0.046 \\
\pm 0.001\end{array}$ \\
\hline $\begin{array}{l}\text { Myricetin-3-O- } \\
\text { rutinoside }^{\mathrm{E}}\end{array}$ & $\begin{array}{l}0.35 \pm \\
0.01\end{array}$ & $\begin{array}{l}0.674 \pm \\
0.001\end{array}$ & $\begin{array}{l}0.279 \pm \\
0.001\end{array}$ & $\begin{array}{l}0.257 \\
\pm 0.001\end{array}$ & - \\
\hline $\begin{array}{l}\text { Myricetin-3-O- } \\
\text { glucoside }^{\mathrm{E}}\end{array}$ & $\begin{array}{l}0.43 \pm \\
0.01\end{array}$ & $\begin{array}{l}0.742 \pm \\
0.001\end{array}$ & $\begin{array}{l}0.355 \pm \\
0.006\end{array}$ & $\begin{array}{l}0.280 \\
\pm 0.001\end{array}$ & $\begin{array}{l}0.306 \\
\pm 0.001\end{array}$ \\
\hline $\begin{array}{l}\text { Myricetin-O- } \\
\text { hexoside }^{\mathrm{E}}\end{array}$ & $\begin{array}{l}0.59 \pm \\
0.01\end{array}$ & $\begin{array}{l}0.676 \pm \\
0.002\end{array}$ & $\begin{array}{l}0.302 \pm \\
0.004\end{array}$ & $\begin{array}{l}0.327 \\
\pm 0.001\end{array}$ & - \\
\hline $\begin{array}{l}\text { Quercetin-O- } \\
\text { deoxyhexosyl- } \\
\text { hexoside-hexoside }{ }^{\mathrm{F}}\end{array}$ & $\begin{array}{l}0.457 \\
\pm 0.008\end{array}$ & $\begin{array}{l}0.138 \pm \\
0.001\end{array}$ & $\begin{array}{l}0.206 \pm \\
0.001\end{array}$ & $\begin{array}{l}0.149 \\
\pm 0.002\end{array}$ & - \\
\hline $\begin{array}{l}\text { Quercetin-O- } \\
\text { deoxyhexosyl- } \\
\text { hexoside-hexoside }\end{array}$ & $\begin{array}{l}0.594 \\
\pm 0.007\end{array}$ & - & $\begin{array}{l}0.067 \pm \\
0.001^{*}\end{array}$ & $\begin{array}{l}0.070 \\
\pm \\
0.001 *\end{array}$ & - \\
\hline $\begin{array}{l}\text { Quercetin-3-O- } \\
\text { glucoside }^{\mathrm{F}}\end{array}$ & $\begin{array}{l}0.25 \pm \\
0.02^{*}\end{array}$ & $\begin{array}{l}0.252 \pm \\
0.001^{*}\end{array}$ & $\begin{array}{l}0.127 \pm \\
0.002^{*}\end{array}$ & $\begin{array}{l}0.129 \\
\pm \\
0.002\end{array}$ & $\begin{array}{l}0.190 \\
\pm 0.001\end{array}$ \\
\hline $\begin{array}{l}\text { Quercetin-3-O- } \\
\text { rutinoside }^{\mathrm{F}}\end{array}$ & - & $\begin{array}{l}0.319 \pm \\
0.001\end{array}$ & - & - & $\begin{array}{l}0.104 \\
\pm 0.003\end{array}$ \\
\hline $\begin{array}{l}\text { Quercetin-O- } \\
\text { deoxyhexosyl- } \\
\text { hexoside }^{\mathrm{F}}\end{array}$ & & $\begin{array}{l}0.167 \pm \\
0.001\end{array}$ & & & $\begin{array}{l}0.085 \\
\pm 0.001\end{array}$ \\
\hline $\begin{array}{l}\text { Quercetin-O-malonyl- } \\
\text { hexoside }^{\mathrm{F}}\end{array}$ & - & $\begin{array}{l}0.196 \pm \\
0.001\end{array}$ & - & - & - \\
\hline $\begin{array}{l}\text { Kaempferol-O- } \\
\text { deoxyhexosyl- } \\
\text { dihexoside }^{\mathrm{F}}\end{array}$ & $\begin{array}{l}0.46 \pm \\
0.01\end{array}$ & - & $\begin{array}{l}0.156 \pm \\
0.002\end{array}$ & $\begin{array}{l}0.220 \\
\pm 0.003\end{array}$ & - \\
\hline $\begin{array}{l}\text { Kaempferol-O- } \\
\text { deoxyhexosyl- } \\
\text { dihexoside }^{\mathrm{F}}\end{array}$ & $\begin{array}{l}0.359 \\
\pm 0.007\end{array}$ & - & $\begin{array}{l}0.065 \pm \\
0.001\end{array}$ & $\begin{array}{l}0.102 \\
\pm 0.001\end{array}$ & - \\
\hline $\begin{array}{l}\text { Kaempferol-3-O- } \\
\text { rutinoside }^{\mathrm{F}}\end{array}$ & $\begin{array}{l}0.154 \\
\pm 0.001\end{array}$ & $\begin{array}{l}0.274 \pm \\
0.001\end{array}$ & $\begin{array}{l}0.058 \pm \\
0.001^{*}\end{array}$ & $\begin{array}{l}0.060 \\
\pm \\
0.001 *\end{array}$ & $\begin{array}{l}0.096 \\
\pm 0.001\end{array}$ \\
\hline $\begin{array}{l}\text { Kaempferol-3-O- } \\
\text { glucoside } \mathrm{F}^{\mathrm{F}}\end{array}$ & $\begin{array}{l}0.084 \\
\pm \\
0.001 *\end{array}$ & $\begin{array}{l}0.218 \pm \\
0.002\end{array}$ & - & - & $\begin{array}{l}0.086 \\
\pm \\
0.001 *\end{array}$ \\
\hline $\begin{array}{l}\text { Kaempferol-O- } \\
\text { malonyl-hexoside }^{\mathrm{F}}\end{array}$ & - & $\begin{array}{l}0.213 \pm \\
0.003\end{array}$ & - & - & - \\
\hline $\begin{array}{l}\text { 3,4-O- } \\
\text { Dicaffeoylquinic } \\
\text { acid }^{\mathrm{B}}\end{array}$ & - & - & - & $\begin{array}{l}0.155 \\
\pm 0.003\end{array}$ & - \\
\hline $\begin{array}{l}\text { 4,5-O- } \\
\text { Dicaffeoylquinic } \\
\text { acid }^{\mathrm{B}}\end{array}$ & - & - & - & $\begin{array}{l}0.127 \\
\pm 0.001\end{array}$ & - \\
\hline $\begin{array}{l}\text { Total phenolic } \\
\text { compounds }\end{array}$ & $\begin{array}{l}44.76 \\
\pm 0.06\end{array}$ & $\begin{array}{l}23.0 \pm \\
0.2\end{array}$ & $\begin{array}{l}9.83 \pm \\
0.04\end{array}$ & $\begin{array}{l}11.27 \\
\pm 0.07\end{array}$ & $\begin{array}{l}11.8 \pm \\
0.2\end{array}$ \\
\hline Total phenolic acids & - & - & - & $\begin{array}{l}3.22 \pm \\
0.01\end{array}$ & - \\
\hline
\end{tabular}


Table 1 (continued)

\begin{tabular}{llllll}
\hline $\begin{array}{l}\text { Tentative } \\
\text { identification }\end{array}$ & $\begin{array}{l}\text { Green } \\
\text { tea } \\
\mathrm{mg} / \mathrm{g} \\
\text { extract }\end{array}$ & $\begin{array}{l}\text { Purple } \\
\text { tea }\end{array}$ & $\begin{array}{l}\text { Oolong } \\
\text { tea }\end{array}$ & $\begin{array}{l}\text { White } \\
\text { tea }\end{array}$ & $\begin{array}{l}\text { Black } \\
\text { tea }\end{array}$ \\
\hline Total flavan3-ols & $\mathbf{4 0 . 3 1}$ & $\mathbf{1 9 . 1} \pm$ & $\mathbf{8 . 1 1} \pm$ & $\mathbf{6 . 3 2} \pm$ & $\mathbf{1 0 . 8} \pm$ \\
& $\mathbf{0 . 0 2}$ & $\mathbf{0 . 2}$ & $\mathbf{0 . 0 4}$ & $\mathbf{0 . 0 8}$ & $\mathbf{0 . 2}$ \\
Total other & $\mathbf{4 . 4 6} \pm$ & $\mathbf{3 . 9 4 3}$ & $\mathbf{0 . 0 4 7} \pm$ & $\mathbf{1 . 7 3} \pm$ & $\mathbf{0 . 9 4 5}$ \\
flavonoids & $\mathbf{0 . 0 8}$ & $\pm \mathbf{0 . 0 0 4}$ & $\mathbf{0 . 0 0 1}$ & $\mathbf{0 . 0 2}$ & $\pm \mathbf{0 . 0 0 2}$ \\
\hline
\end{tabular}

Standard calibration curves: $\mathrm{A}$ - catechin $\left(\mathrm{y}=84950 \mathrm{x}-23200, \mathrm{R}^{2}=1 ; \mathrm{LOD}=\right.$ $0.17 \mu \mathrm{g} / \mathrm{mL}$; LOQ $=0.68 \mu \mathrm{g} / \mathrm{mL})$; B- chlorogenic acid $(\mathrm{y}=168823 \mathrm{x}-161172$, $\mathrm{R}^{2}=0.9999 ; \mathrm{LOD}=0.20 \mu \mathrm{g} / \mathrm{mL}$; LOQ $\left.=0.68 \mu \mathrm{g} / \mathrm{mL}\right) ; \mathrm{C}-$ gallic acid $(\mathrm{y}=$ $\left.131538 \mathrm{x}+292163, \mathrm{R}^{2}=0.9969 ; \mathrm{LOD}=0.28 \mu \mathrm{g} / \mathrm{mL} ; \mathrm{LOQ}=0.87 \mu \mathrm{g} / \mathrm{mL}\right) ; \mathrm{D}-$ apigenin-6-C-glucoside ( $\mathrm{y}=107025 \mathrm{x}+61531, \mathrm{R}^{2}=0.9989 ; \mathrm{LOD}=0.19 \mu \mathrm{g}$ / $\mathrm{mL}$; LOQ $=0.63 \mu \mathrm{g} / \mathrm{mL})$; E - myricetin-3-O-glucoside $\left(\mathrm{y}=23287 \mathrm{x}-581708, \mathrm{R}^{2}\right.$ $=0.9988 ; \mathrm{LOD}=0.23 \mu \mathrm{g} / \mathrm{mL} ; \mathrm{LOQ}=0.78 \mu \mathrm{g} / \mathrm{mL}$ ); F- quercetin-3-O-glucoside ( $\mathrm{y}=34843 \mathrm{x}-160173, \mathrm{R}^{2}=0.9998 ; \mathrm{LOD}=0.21 \mu \mathrm{g} / \mathrm{mL} ; \mathrm{LOQ}=0.71 \mu \mathrm{g} / \mathrm{mL}$ ). Values labeled with the same symbols (* or ${ }^{\natural}$ ) in the same line do not differ statistically from each other, as indicated by variance analysis followed by Student-Newman-Keuls post hoc testing.

ambiguities resulting from the use of the LC-MS methodology.

The modeled structure of porcine pancreatic alpha-amylase bonded to the inhibitor acarbose pentasaccharide (ARE) was used in the simulations (Kato-Schwartz et al., 2020). The details of the simulations followed the protocol described previously (Kato-Schwartz et al., 2020) with modifications. In summary, the structures of the compounds were evaluated by four different programs, in each case with four replications. The protocols for the Autodock (Morris et al., 2009), Molegro (Thomsen \& Christensen, 2006) and Gold (Jones, Willett, Glen, Leach, \& Taylor, 1997) programs were as described previously (Kato-Schwartz et al., 2020). The analyses with the DockThor program (Santos, Guedes, Karl \& Dardenne, 2020) followed the default settings. The scores provided by each program were compared with the scores of the amylose pentasaccharide substrate or the modeled acarbose inhibitor. Since each program generates scores whose numerical values can not be directly compared, a mean relative score for each compound was calculated according to the following relation:

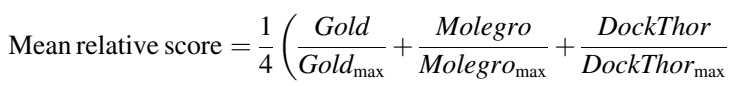

$$
\begin{aligned}
& \left.+\frac{\text { Autodock }}{\text { Autodock }_{\max }}\right)
\end{aligned}
$$

Gold $_{\max }$, etc., corresponds to the score of the compound to which the maximal numerical value was attributed by each program. This normalization may be lumping together numbers that might have different meanings and should be regarded as an attempt at obtaining an unified comparative perspective over a great number of diverse substances.

\subsection{Starch tolerance assay in mice}

The starch tolerance test was done as described previously (Kato et al., 2017; da Silva et al., 2014) with modifications. Fasted (18 h) male Swiss mice (25-35 g) were used and the administration route was in all cases intragastric (by gavage). The number of animals for each experimental approach was between 3 and 4 . Controls received solely commercial corn starch ( $1 \mathrm{~g} / \mathrm{kg}$ body weight). Filtered tap water was administered for establishing a base line. The extracts derived from the various teas were administered at doses of up to $500 \mathrm{mg} / \mathrm{kg}$ before starch administration. Acarbose, a classical inhibitor of starch hydrolysis and digestion, was administered at doses of up to $50 \mathrm{mg} / \mathrm{kg}$ before starch administration. Plasma glucose was determined at times 0, 30, 60, 90, and $120 \mathrm{~min}$ after starch administration. The extract dose was based on literature data. Blood samples were collected from the tail vein and analysed by means of a glucometer (AccuChek ${ }^{\circledR}$ ) for determining the plasma glucose concentration.

\subsection{Glucose and maltose tolerance assays in mice}

For the glucose and maltose tolerance assays $18 \mathrm{~h}$ fasted mice were used. Glucose or maltose were administered intragastrically to all animals $(1.5 \mathrm{~g} / \mathrm{kg})$ except to those that received just filtered tap water to establish the basal line. The tea extracts were administered to different groups animals at the dose of $250 \mathrm{mg} / \mathrm{kg}$ before glucose or maltose administration. Blood samples were collected from the tail vein at times $0,30,60,90$ e $120 \mathrm{~min}$ and analysed by means of a glucometer (Accu-

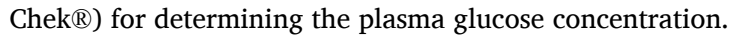

\subsection{Statistical analysis and calculations}

Statistical analysis was performed using the GraphPad Prism software (version 8.0). The results were expressed as the mean \pm standard errors, and were analysed using one-way analysis of variance (one-way ANOVA), followed by post-hoc Student-Newman-Keuls testing. The 5\% level was adopted as a criterion of statistical significance. Numerical interpolation (Stineman's formula) was used for evaluating the $\mathrm{IC}_{50}$ values of the $\alpha$-amylase by the various tea extracts. The calculations were done using the Scientist software from MicroMath Scientific Software (Salt Lake City, UT).

\section{Results}

\subsection{Chemical constituents of the extracts}

Phenolic compounds are generally believed to constitute the main bioactive compounds and inhibitors of $\alpha$-amylases in Camellia sinensis extracts and, for this reason, all extracts used in this study were characterized in terms of their contents in these compounds, using the analytical procedures described in the Section 2 .

Table 1 gives the contents of each identified phenolic compound in the extracts of the various tea varieties. Details such as retention time (Rt), wavelengths of maximum absorption in the visible region $\left(\lambda_{\max }\right)$, mass spectral data, and fragmentation pattern can be found in Supplementary Material (Tables 1S-5S). The identification of (+)-catechin, 5$O$-caffeoylquinic acid, myricetin-3-O-rutinoside, myricetin-3-O-glucoside, quercetin-3-O-glucoside, quercetin-3-O-rutinoside, kaempferol-3$O$-rutinoside, and kaempferol-3-O-glucoside was made by comparison with authentic available standards. The remaining compounds were tentatively identified by comparing their chromatographic characteristics with results previously described in literature (Dou, Lee, Tzen, Lee, 2007; Kim, Goodner, Park, Choi, Talcott, 2011; Zielinski, Haminiuk, Beta, 2016). The contents are all expressed as quantities (mg) per gram extract and they represent the amounts that were effectively extracted using the procedure described in the methods section (mild hot water extraction). In terms of the contents of total phenolic compounds, the decreasing sequence is green tea $>$ purple tea $>$ black tea $\approx$ white tea $>$ oolong tea. Individually, epigallocatechin gallate is the most abundant compound in all extracts, the decreasing sequence being green tea $>$ purple tea $>$ black tea $>$ white tea $\approx$ oolong tea. The purple tea extract revealed to possess the by far highest content of the (epi)gallocatechin isomer 1, 7.9 times more than green tea, which ranked second in this respect. The green tea, however, exceeded the purple tea extract in having 2.7 times more $(+)$ catechin and 2.59 times more epigallocatechin gallate. Finally, phenolic acids were found only in the white tea extract; on the other hand, a theasinensin, B or E, was found only in the black tea extract.

With respect to the total content of anthocyanins, the difference between the purple tea extract and all other extracts is remarkable. The purple tea extract revealed to possess $0.9 \pm 0.1 \mathrm{mg}$ cyanidin-3-Oglucoside equivalents/g extract, while all other extracts presented 0.100 $\pm 0.005 \mathrm{mg}$ cyanidin-3-O-glucoside equivalents/g extract (black tea) or 
less (oolong, white and green tea).

The content of polysaccharides, another possible source of inhibitory compounds (Deng et al., 2015), of white, oolong, green, purple and black tea were, respectively, $113 \pm 10,62 \pm 1,43 \pm 2,24 \pm 1$ and 23.7 $\pm 0.2 \mathrm{mg}$ glucose equivalents per $\mathrm{g}$ extract.

\subsection{Effects of the tea varieties on the porcine pancreatic $\alpha$-amylase}

Our first approach to the possible effects of the five tea extracts on the biological components involved in starch digestion was to measure the activity of the pancreatic $\alpha$-amylase. The enzyme used was the
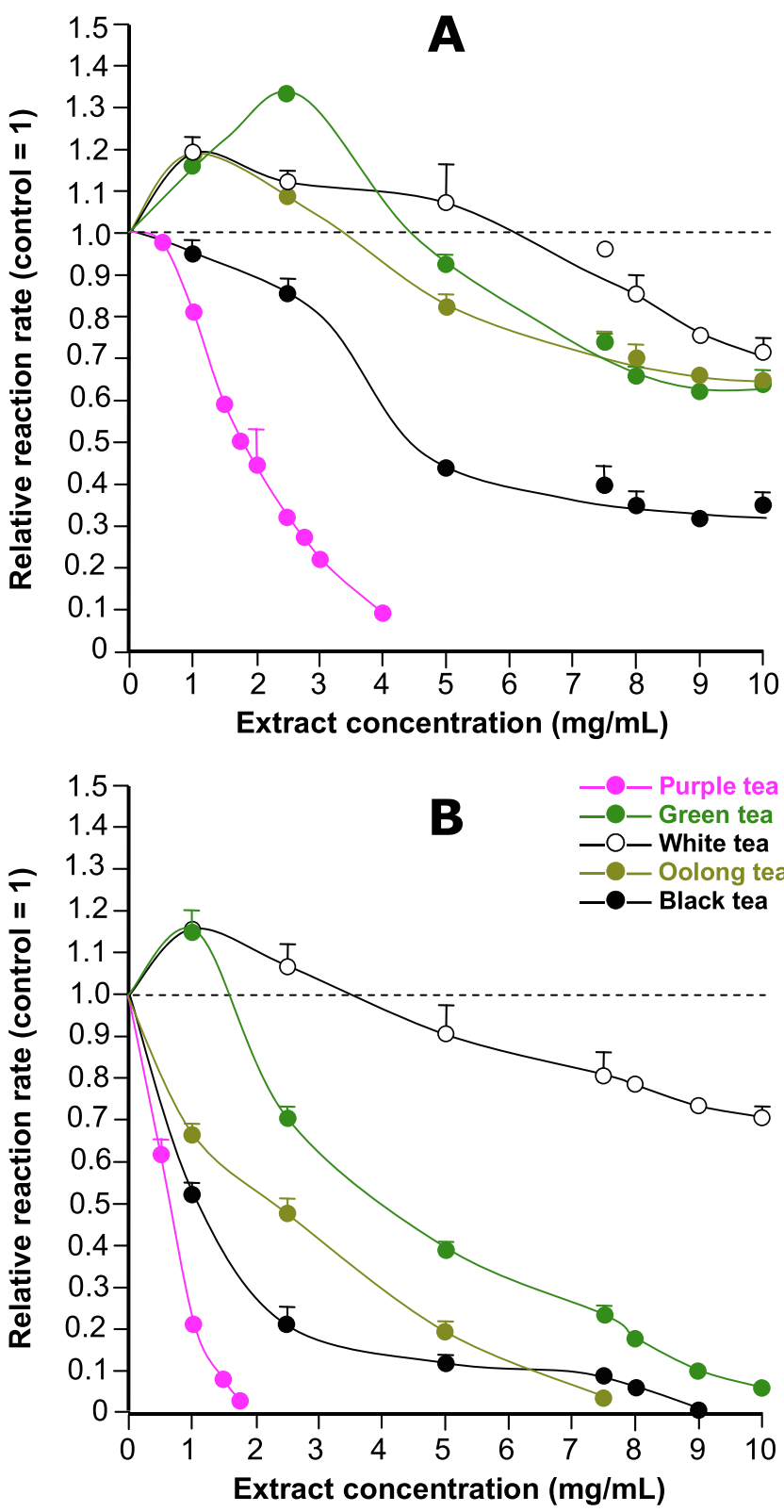

Fig. 1. Dependences of the activity of the porcine pancreatic $\alpha$-amylase on the concentration of the various tea extracts. The reaction rates in the presence of the various extracts were represented as fractions of the rate measured in the absence of the extracts (control =1). Each datum point is the mean of three determinations. Standard errors of the mean cannot be seen when smaller than the symbols. Panel A shows the reaction rates that were measured when the reaction was started by adding the enzyme after pre-incubation of the substrate with the extract; panel $\mathrm{B}$ shows the reaction rates that were measured when the reaction was started by adding the substrate after a pre-incubation of the enzyme with the extract (see details in the Material and Methods section). commercially available porcine pancreatic $\alpha$-amylase. Fig. 1A shows the results that were obtained when the reaction was initiated by the addition of the substrate (starch at a final concentration $1 \mathrm{~g} / 100 \mathrm{~mL}$ ) after pre-incubation of the enzyme with the various extracts. Data were expressed as relative rates, the control reaction rate being defined as unity. In this assay three extracts were clearly stimulatory at low concentrations, namely green tea, white tea and oolong tea. Inhibition, however, took place at higher concentrations, though it was not very pronounced for concentrations up to $10 \mathrm{mg} / \mathrm{mL}$ in the case of green, white and oolong teas. Black tea and purple tea, on the other hand, were inhibitory over the whole concentration range that was employed, purple tea being by far the most effective one with more than $90 \%$ inhibition at the concentration of $4 \mathrm{mg} / \mathrm{mL}$. The $\mathrm{IC}_{50}$ value for purple tea was equal to $1.74 \mathrm{mg} / \mathrm{mL}$ and that of black tea $4.29 \mathrm{mg} / \mathrm{mL}$. For all other teas the $\mathrm{IC}_{50}$ can be expected to be above $10 \mathrm{mg} / \mathrm{mL}$.

The results that were obtained using the second protocol, i.e., when the reaction was started by addition of the substrate after pre-incubation of the extracts with the enzyme, are shown in Fig. 1B. Under this protocol, stimulation at low concentrations was absent in the case of oolong tea and considerably reduced and restricted to the lowest concentration ranges in the case of green and white teas. The inhibition degree, on the other hand, was substantially increased in all cases, as revealed by visual inspection and, with more precision, by the corresponding IC $_{50}$ values which were: $0.63 \mathrm{mg} / \mathrm{mL}$ for purple tea, $1.09 \mathrm{mg} / \mathrm{mL}$ for black teat, 2.24 $\mathrm{mg} / \mathrm{mL}$ for oolong tea and $3.97 \mathrm{mg} / \mathrm{mL}$ for green tea. Solely for white tea the $\mathrm{IC}_{50}$ value remained above $10 \mathrm{mg} / \mathrm{mL}$.

The inhibition revealed by Fig. 1 can be caused by low molecular weight compounds (e.g., phenolic compounds), but macromolecules could equally be involved. Putative candidates are polysaccharides, which are present in Camellia sinensis preparations (Scoparo et al., 2016) and that have been demonstrated to be able to inhibit digestive enzymes (Deng et al., 2015). To get an insight into this possibility the solubilized extracts used in the experiments shown in Fig. 1 were treated with ethanol, which precipitates macromolecules, especially polysaccharides. The precipitates were solubilized in the same water volume as the original extract solution and used in $\alpha$-amylase assays of the kind shown in Fig. 1. Fig. 2 allows to compare the activities of the pancreatic $\alpha$-amylase in the presence of the total aqueous extracts (AE) of the various $C$. sinensis varieties with the activities in the presence of the corresponding re-solubilized ethanol precipitates (EP). For each pair of columns ( $\mathrm{AE}$ and $\mathrm{EP}$ ) the extract concentrations were those that produced the maximally observed inhibition in the experiments shown in Fig. 1. Panel A shows the reaction rates that were measured when the reaction was started by adding the enzyme after pre-incubation of the substrate with the aqueous extract or re-solubilized ethanol precipitate. Using this procedure, no inhibition was found for the re-solubilized precipitate. Instead, a tendency toward stimulation can be identified for purple tea. Panel B shows the reaction rates that were measured when the reaction was started by adding the substrate after a preincubation of the enzyme with the aqueous extract or re-solubilized ethanol precipitate. In this case, purple and oolong tea presented small inhibitions when compare to the great inhibitory activity of the total aqueous extract. The black tea re-solubilized ethanol precipitate, on the other hand, inhibited the $\alpha$-amylase activity by $29 \%$, comprising, thus, a significant fraction of the inhibition caused by the total aqueous extract.

\subsection{In silico studies}

The tea extracts contain many compounds (Table 1) and their isolation for testing the inhibitory activity on the $\alpha$-amylases can be quite laborious. Computer simulations may give a hint about the compounds (or compound) that are more likely to act as inhibitors of the $\alpha$-amylases.

The list in Table 1 presents some ambiguities that could not be resolved so that possible variations that were available in PubChem 

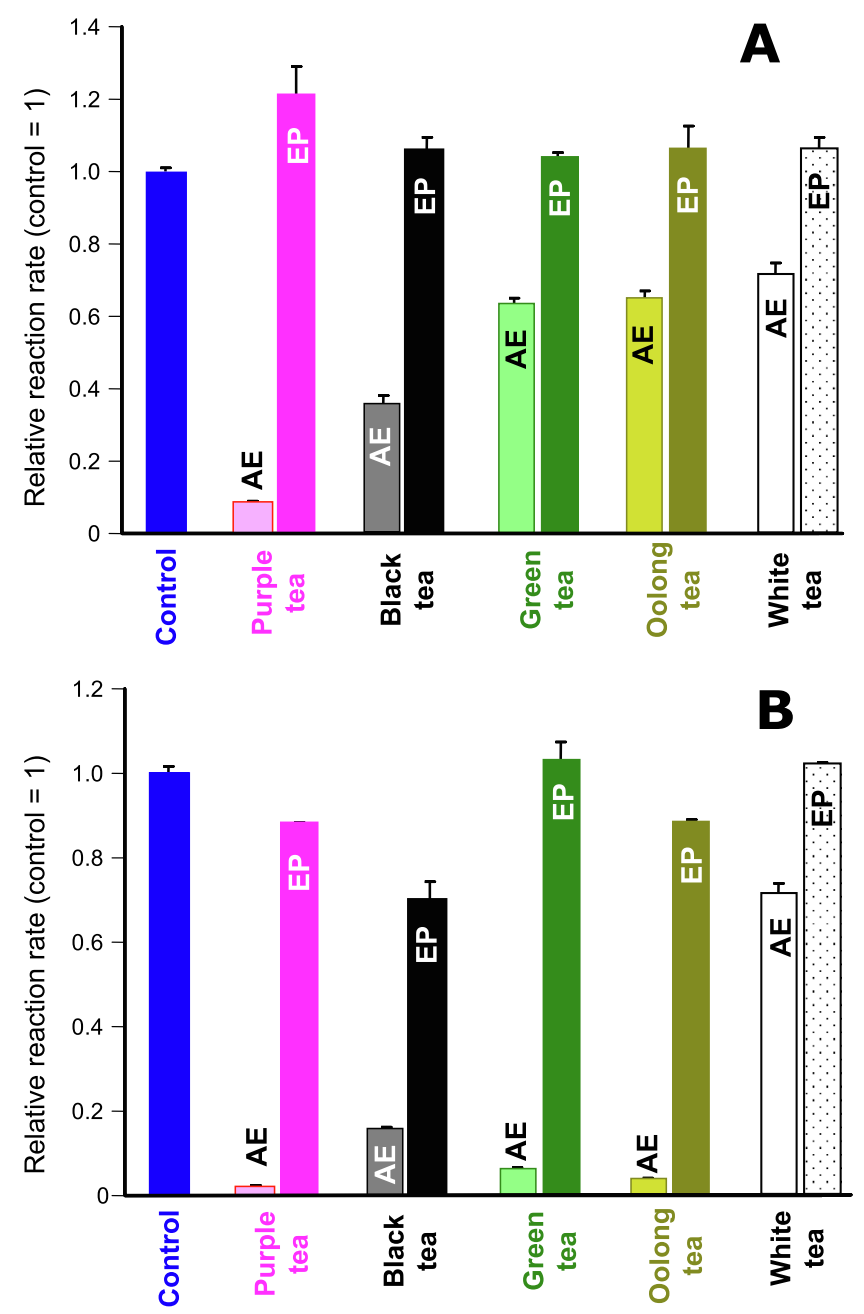

Fig. 2. Comparison of the activities of the pancreatic $\alpha$-amylase in the presence of the total aqueous extracts (AE) of the various $C$. sinensis varieties with the activities in the presence of the corresponding re-solubilized ethanol precipitates (EP). For each pair of columns (AE and EP) the extract concentrations were those that produced the maximally observed inhibition in the experiments shown in Fig. 1. Panel A shows the reaction rates that were measured when the reaction was started by adding the enzyme after pre-incubation of the substrate with the aqueous extract or re-solubilized ethanol precipitate; panel B shows the reaction rates that were measured when the reaction was started by adding the substrate after a pre-incubation of the enzyme with aqueous extract or resolubilized ethanol precipitate (see details in the Material and Methods section).

were considered. On doing so, the library with the evaluated compounds ended up by containing 36 molecules plus the acarbose pentasaccharide inhibitor and the amylose pentasaccharide substrate. The list with the names and respective PubChem identification codes (CID) for the compounds used in the simulations is shown in Table $6 \mathrm{~S}$. The average scores obtained with four simulations for each docking program are shown in Table 7S. The graph of Fig. 3 shows in pictorial form the mean relative scores, calculated according to equation (3), in decreasing order.

The compound with the highest binding probability according to the mean relative scores shown in Fig. 3 is kaempferol-O-rutinoside-hexoside, (represented by the molecule kaempferol-3-O-rutinoside 7-Oglucoside, CID 21676298). The distance in terms of the mean relative score between this molecule and that one ranked in second place, namely myericetin-3-O-rutinosde, is more pronounced than the differences between the molecules ranked between 2 and 9. Notable, however, is the result that among the ten best ranked molecules, 7 of them are rutinosides. Fig. 3 also reveals that the catechins, often considered
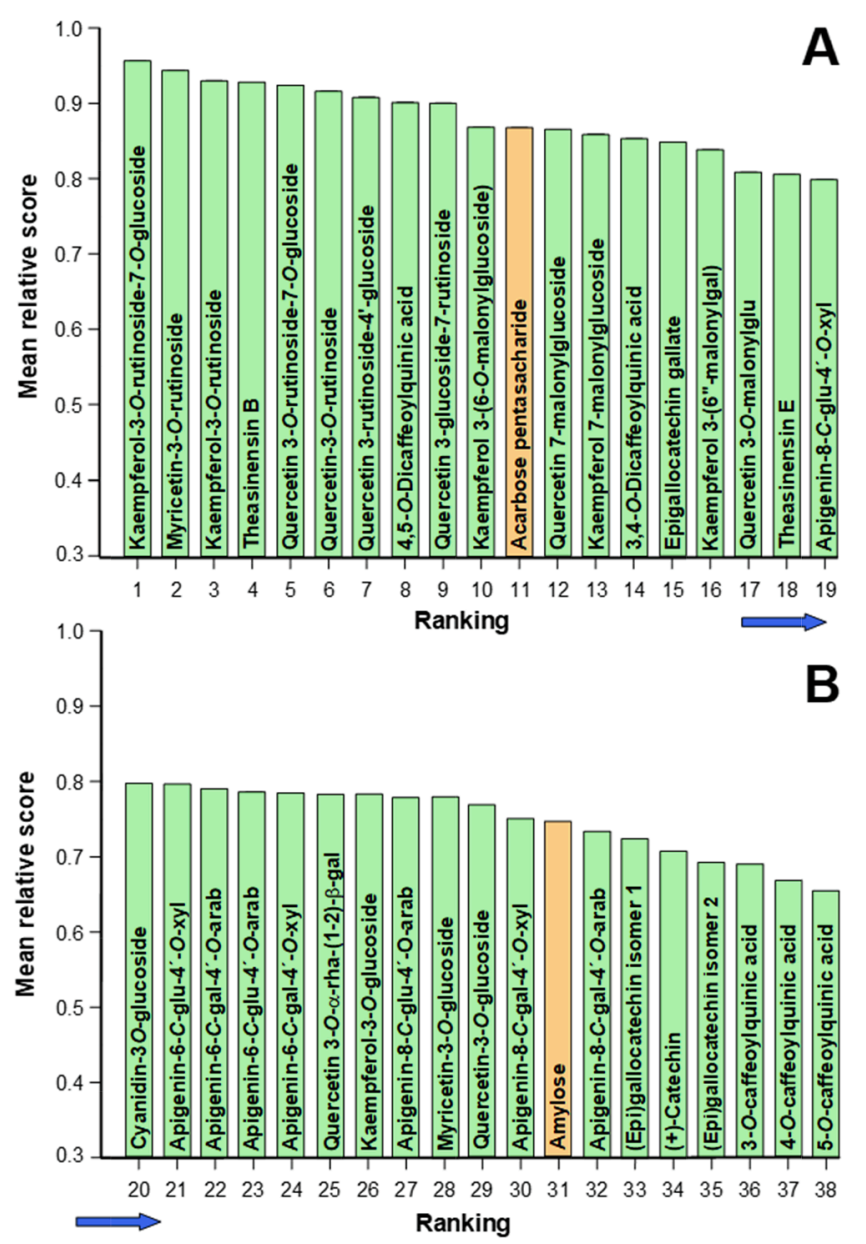

Fig. 3. The compounds quantified in the Camellia sinensis varieties displayed according to their decreasing mean relative scores, as defined by equation (3). Abbreviations: glu, glucoside; xyl, xyloside; gal, galactoside or galactopyranoside specifically for the compound ranked 25; arab, arabinoside; rham, rhamnopyranosyl.

important bioactives of Camellia sinensis, especially green tea, do not appear in the first positions. The best ranked is epigallocatechin gallate (15), whereas $(+)$-catechin itself ranks only 33. Fig. 3 also reveals that cyanidin-3-O-glucoside, the main responsible for the characteristic colour of the purple tea leaves appears in position 20 .

\subsection{Effects of purple tea and other varieties on starch digestion}

It is important to find out if the effects of tea extracts on the $\alpha$-amylases have physiological relevance, i.e., if they also occur in vivo. Since starch must be hydrolyzed within the intestinal lumen before glucose absorption occurs, the data in Fig. 1 suggest that the purple tea should be the best inhibitor of the phenomenon. This question was approached in the present work by means of the starch tolerance test. Experiments were done with all the five tea extracts. The extracts were given intragastrically to mice at doses of $500 \mathrm{mg} / \mathrm{mL}$. The extract administration was followed by intragastric starch administration and the plasma glucose concentration was followed at intervals from zero time to 120 min. All results of this experimental series are summarized in Fig. 4.

As observed from previous reports (Kato et al., 2017; da Silva et al., 2014) the administration of starch resulted in pronounced transiently elevated plasma glucose concentrations. Administration of water produced a small increment in glucose concentration, generally attributable to the mild stress to which the mice are undergoing in consequence of the experimental manipulations. Previous administration of the various 

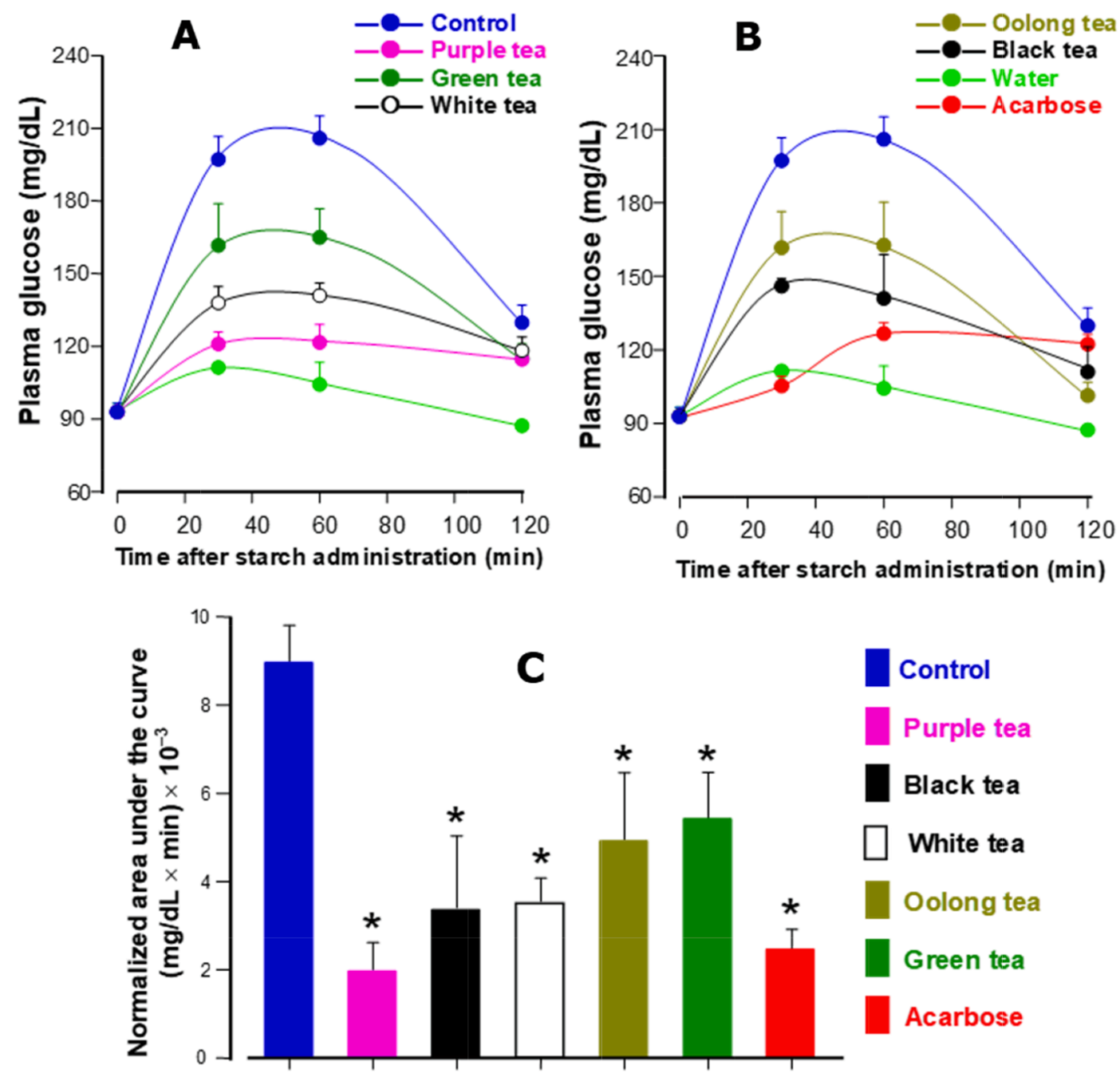

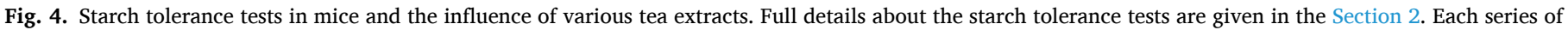

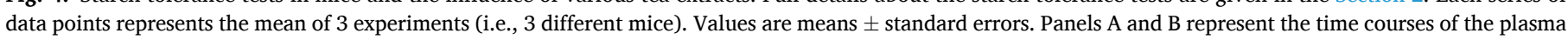

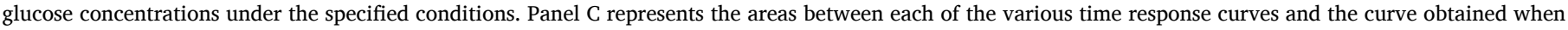

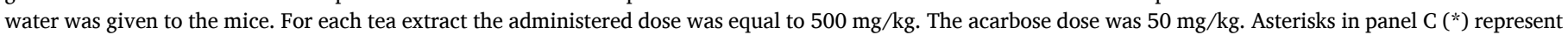
statistical significance at the 5\% level relative to the control condition according to the Student-Newman-Keuls test.

tea extracts modified the responses of the mice in all cases, with a kinetics that was somewhat different to that one observed when acarbose, the classical inhibitor of starch digestion, was given. Even visual inspection of the various curves in panels A and B of Fig. 4 allows to conclude that the actions of the various teas were different and that the purple tea extract was likely to be the most effective in diminishing glycemia in consequence of starch digestion. A more precise evaluation of the effects of the various teas is given by panel C of Fig. 4 in which the areas between the various test curves and the curve obtained when water was given alone to the mice were represented. These areas are generally regarded as a quantitative measure of the delay in starch digestion caused by specific agents including acarbose. Fig. 4C confirms that all tea extracts, at the doses that were administered in each case $(500 \mathrm{mg} / \mathrm{kg}$ ), caused inhibition of starch digestion, but that purple tea was the most effective one, with $80 \%$ inhibition. The least inhibitory was green tea, with a $40 \%$ diminution.

Starch tolerance tests were also done in mice that received different doses of the purple tea extract in an attempt at establishing a dose-effect relationship. The results are shown in Fig. 5. The peak of the curve obtained with the $50 \mathrm{mg} / \mathrm{kg}$ dose of the purple tea was under the control peak (Fig. 5A), but the normalized area (Fig. 5B) was not significantly different from the control area under the statistical criteria adopted in this work. The effect reached statistical significance, however, with the $100 \mathrm{mg} / \mathrm{kg}$ dose and the $250 \mathrm{mg} / \mathrm{kg}$ dose already producing an effect that was no longer statistically different from that one observed with the $500 \mathrm{mg} / \mathrm{kg}$ dose.

Experiments were also done with different doses of the green tea extract in an attempt at detecting a possible stimulatory effect on starch digestion, which is suggested by the stimulatory effect of this tea variety on the $\alpha$-amylase activity (see Fig. 1). The results of this experimental series are shown in Fig. 6. Low doses of up to $100 \mathrm{mg} / \mathrm{kg}$ were given because stimulation is expected to occur at low concentrations. Panel A in Fig. 6 reveals that the dose of $50 \mathrm{mg} / \mathrm{kg}$ was ineffective in modifying starch digestion, but the $100 \mathrm{mg} / \mathrm{kg}$ dose was clearly inhibitory. Stimulation, on the other hand, did not occur when the doses were reduced to 25 and $5 \mathrm{mg} / \mathrm{kg}$, as revealed by panel B of Fig. 6. Actually, the doses from 5 to $50 \mathrm{mg} / \mathrm{kg}$ did not affect starch digestion at all, as clearly indicated by the areas under the curves that are shown in Fig. 6C. Singularly, the transition between absence of inhibition and maximal or nearly maximal inhibition took place within the interval between 50 and $100 \mathrm{mg} / \mathrm{kg}$ because the latter dose caused an inhibition that was very similar to that one previously found with the $500 \mathrm{mg} / \mathrm{kg}$ dose. 

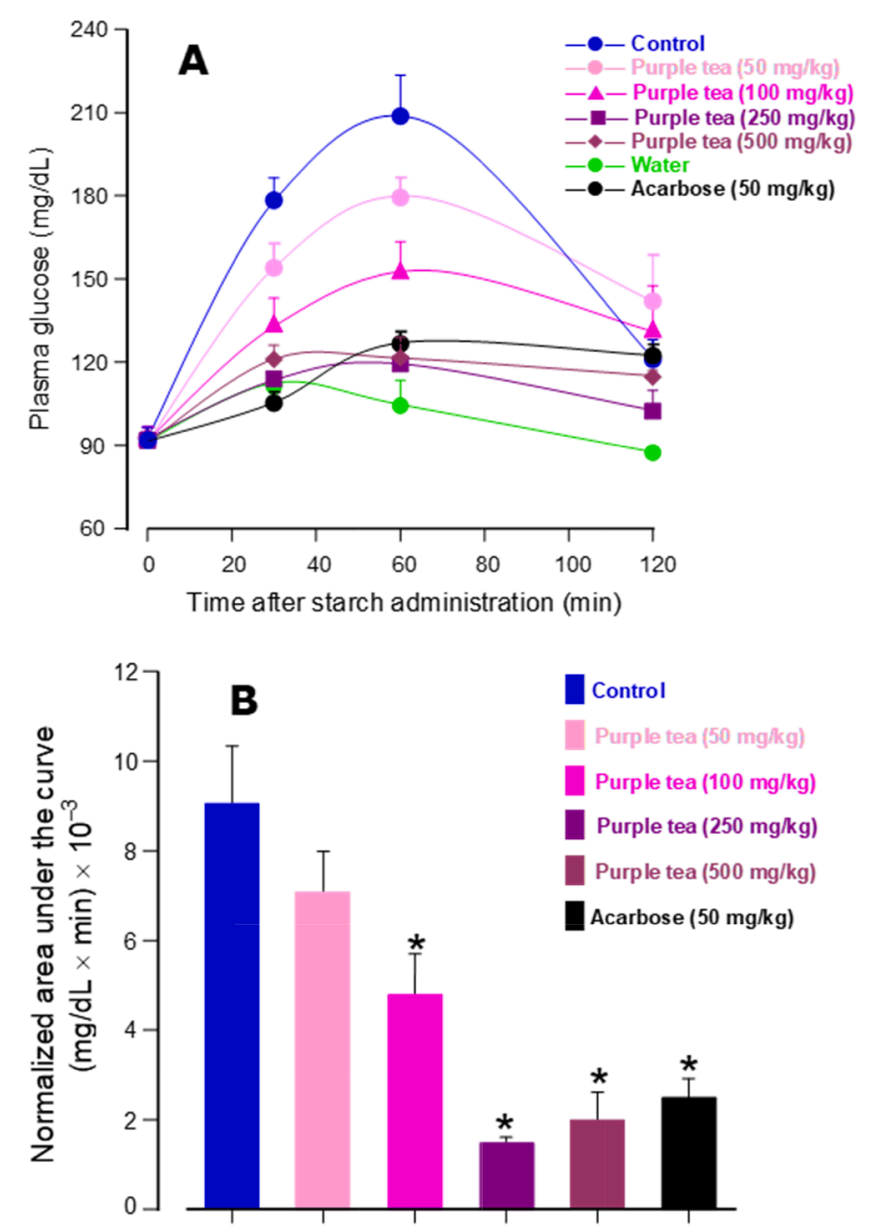

Fig. 5. Starch tolerance tests in mice and the influence of various purple tea extract doses. Full details about the starch tolerance tests are given in the Section 2. Each series of data points represents the mean of 3 experiments (i.e., 3 different mice). Values are means \pm standard errors. Panel A represents the time courses of the plasma glucose concentrations under the specified conditions. Panel B represents the areas between each of the various time response curves and the curve obtained when water was given to the mice. Asterisks in panel B (*) represent statistical significance at the $5 \%$ level relative to the control condition according to the Student-Newman-Keuls test. (For interpretation of the references to color in this figure legend, the reader is referred to the web version of this article.)

\subsection{Effects of purple tea and other varieties on maltose and glucose tolerance}

Diminution of the hyperglycemic burst in consequence of a maltose load can be expected if hydrolysis of this disaccharide in the intestine is strongly inhibited (Adisakwattana et al., 2011). In order to investigate this possibility maltose tolerance tests were performed using the same protocol employed in the starch tolerance tests. Since this work is focused mainly on the effects of purple tea, the dose of $250 \mathrm{mg} / \mathrm{kg}$ was chosen because it had already maximal effect on starch digestion. The results are shown in Fig. 7. From the time courses (Fig. 7A and B) it is apparent that the effects of the various tea extracts are minimal, excepting perhaps the white tea extract. The differential areas in Fig. 7C confirm this conclusion. There are very weak tendencies toward stimulation, especially in the case of oolong tea, but the statistical dispersion prohibits any definitive conclusion. Much stronger is the tendency of a delay in maltose digestion caused by the white tea extract. However, also in this case, statistical significance at the $5 \%$ level is lacking.

The final experiments that were done in this work were glucose tolerance tests. Glucose absorption depends of an active transport system (Thorsen, Drengstig \& Ruoff, 2014), which could eventually be inhibited (or activated) by one or more of the extracts used in the present work. The results of the pertinent experiments are shown in Fig. 8. Here again the doses were $250 \mathrm{mg} / \mathrm{kg}$. The curves obtained with the purple tea extract, shown in panel A, seem to run very close to the control curve. The same can be said about the curves obtained with the white tea extract (panel A) and oolong tea extract (panel B). The curves obtained after administrating both black and green extracts, however, showed a clear tendency of running well above the control curve, especially in their final portions. This was confirmed when the differential areas were calculated and represented in graphical form in panel C of Fig. 8. The black tea extract clearly diminished glucose tolerance (i.e., the hyperglycemic burst was prolonged) in comparison with the control. The green tea extract presented the same tendency, without statistical significance however.

\section{Discussion}

\subsection{General aspects of the action of the Camellia sinensis extracts on starch digestion}

The main question to be responded by this study was if aqueous extracts of different Camellia sinensis varieties, prepared under identical conditions, can eventually act as similar or different inhibitors of the pancreatic $\alpha$-amylase and of starch digestion in mice. In this respect the data revealed that purple tea was undoubtedly the best inhibitor of both pancreatic $\alpha$-amylase and starch digestion. Black tea was the next best inhibitor of both $\alpha$-amylase and starch digestion. However, with respect to the latter phenomenon no strict correlation could be established between the inhibition of the $\alpha$-amylase and starch digestion. White tea, for example, was the by far least effective inhibitor of the $\alpha$-amylase, but its capacity in inhibiting starch digestion was similar to that of the black tea. With respect to green tea, which ranked among the least effective inhibitors of starch digestion, the results are particularly surprising for two main reasons: (1) firstly because green tea has been proposed by several investigators as an effective inhibitor of starch digestion based mainly on results obtained with isolated enzymes (Gao et al., 2013; Miao et al., 2015; Nyambe-Silavwe et al., 2015), but also on at least one in vivo study (Lochocka et al., 2015); (2) the green tea extract used in the present work was the preparation that presented the highest content in total phenolic compounds, actually nearly twice as much as the purple tea extract. Several phenolic compounds, including some that are abundant in green tea, have been reported to act as $\alpha$-amylase or $\alpha$-glucosidase inhibitors (D'Costa \& Bordenave, 2021; Desseaux, Stocker, Brouant \& Ajandouz, 2018), but in the present work green tea was also a relatively weak inhibitor of the $\alpha$-amylase under our assay conditions. The role of $\alpha$-amylase inhibition seems to be predominant for the in vivo effects observed in the present study. This is based on the observation that maltose tolerance was not affected by any of the various extracts, except perhaps for a non-significant tendency that was observed with white tea. A possible inhibition of $\alpha$-glucosidase in vivo should have affected maltose tolerance. The results of the glucose tolerance tests, on the other hand, may be taken as an indication that the various tea extracts are not able to inhibit glucose absorption by the intestine, which is an energy-dependent process (Thorsen et al., 2014). Remarkably, however, black tea diminished glucose tolerance in a significant way and green tea presented the same tendency. This kind of effect is difficult to interpret because there are several possibilities, all of them contributing to the modifications in the starch tolerance test, which would no longer be reflecting solely the hydrolysis inhibition. Stimulation of glucose absorption is one of these possibilities. Another one is inhibition of glucose transformation. There are no data available, however, to distinguish between these or other possibilities. 


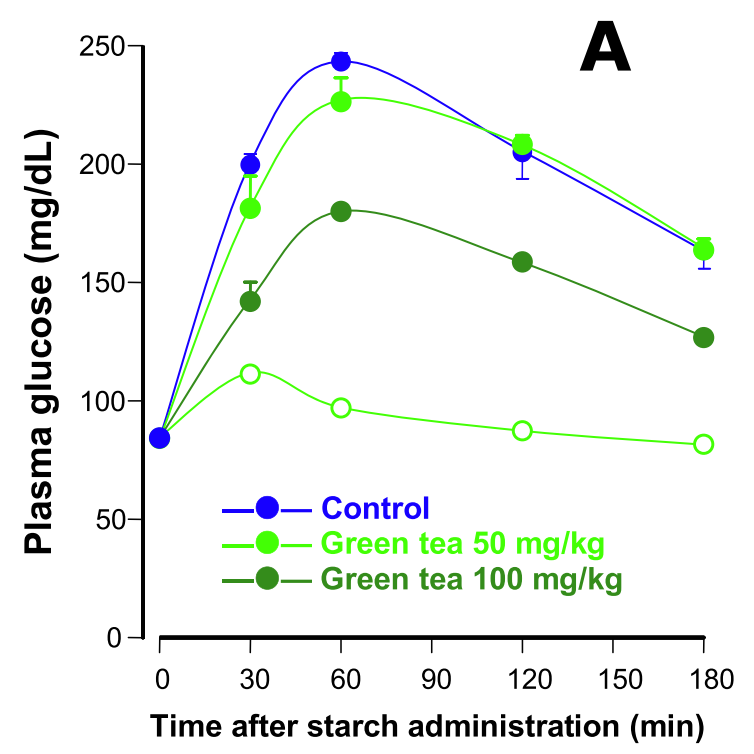

Time after starch administration ( $\mathrm{min})$

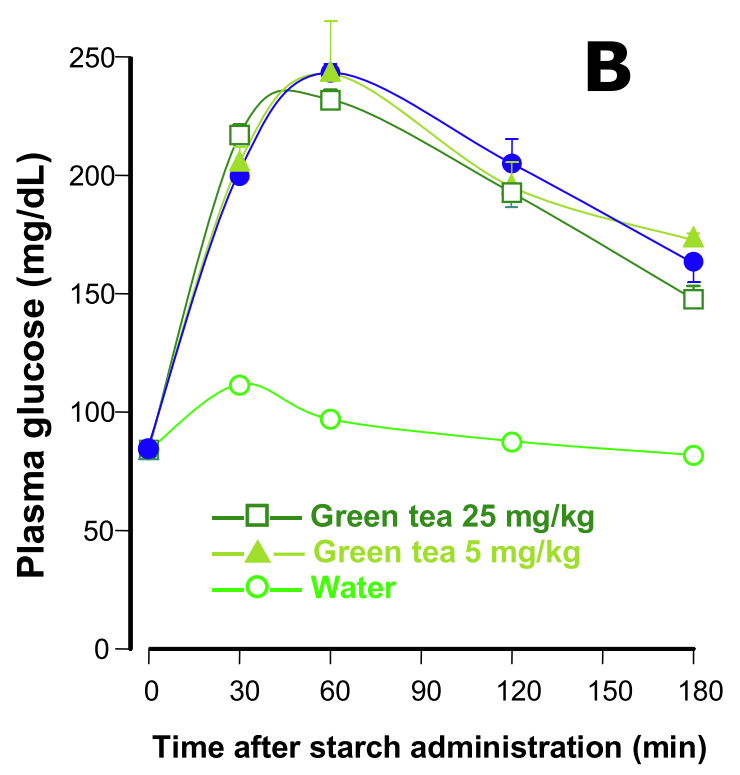

C

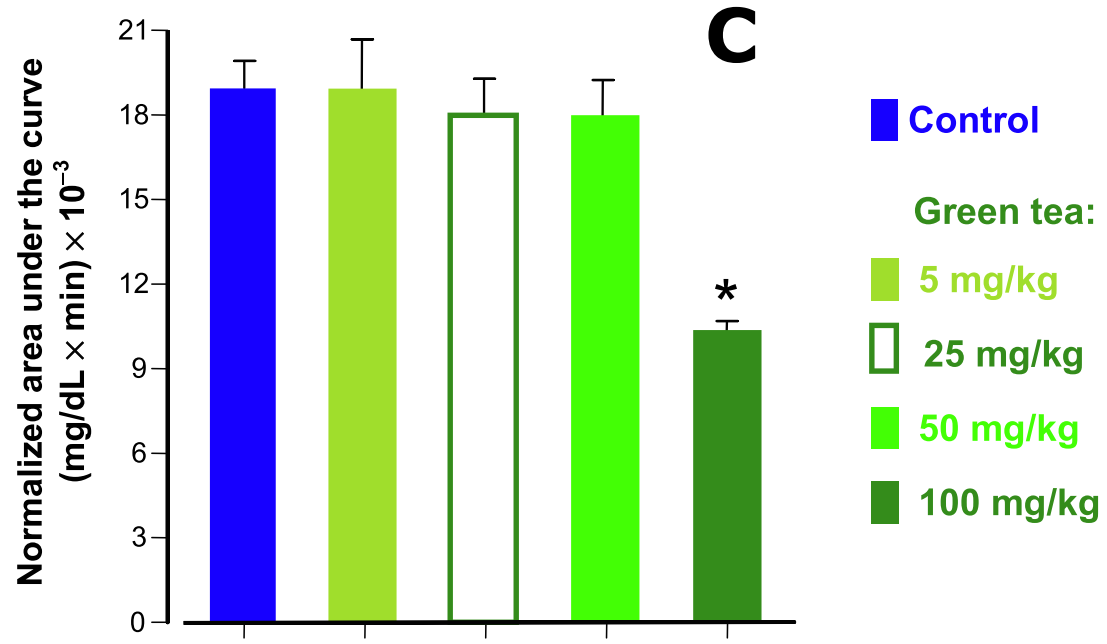

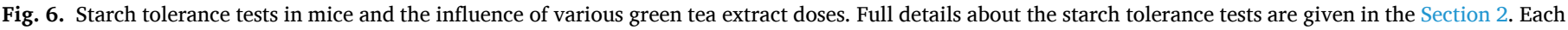

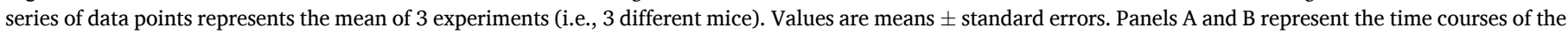

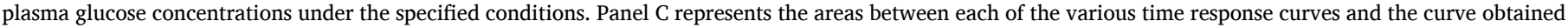

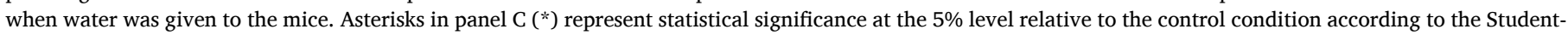
Newman-Keuls test. (For interpretation of the references to color in this figure legend, the reader is referred to the web version of this article.)

\subsection{The role of $\alpha$-amylase}

In favor of the widespread hypothesis that the pancreatic $\alpha$-amylase plays an important role in starch digestion and that its inhibition may also lead to a diminution of the phenomenon is the observation that the purple tea extract was by far the most potent inhibitor of the enzyme. Black tea was the second most effective inhibitor, an observation that also agrees with the action of this tea variety on starch digestion. The other types of tea, however, were actually stimulators of the pancreatic $\alpha$-amylase at low concentrations, the inhibitory activity being effective only at quite high concentrations. Stimulation at low concentrations is not so surprising as it seems, because the phenomenon has already been reported before (Yang \& Kong, 2016). Actually, as mentioned in the Introduction, data on the in vitro $\alpha$-amylase and $\alpha$-glucosidase inhibition by Camellia sinensis extracts present extreme variations from report to report so that translation to the in vivo conditions becomes extremely uncertain. An at least partly positive correlation between the in vitro and in vivo inhibitory actions, as it was the case in the present study with the purple tea and black tea extracts, seems not to be very frequent. This may be caused by the fact that it is very difficult to reproduce in the test tube the conditions that predominate in the intestine once both starch and the various chemical constituents of a given extract get in contact. In this respect it looks important to list the various factors that may be different in the in vitro systems when compared to the in vivo situation. In most cases the porcine pancreatic $\alpha$-amylase is used, but the animal used for experimentation is frequently a rodent and enzymes from different species may react differently to the inhibitors. This is a reasonable supposition, but there are yet no experimental data corroborating it. Furthermore, the initial reaction rates are generally measured in vitro under standardized conditions without pre-incubation. Pre-incubation with the enzyme, however, clearly enhances the inhibitory effects, as it has been demonstrated in the present study, corroborating previous observations with tea extracts and their pure constituents (D'Costa \& Bordenave, 2021; Yang \& Kong, 2016). In this respect it is worth to recall that the starch tolerance test takes at least two hours to be completed, so that there would be enough time for an enhancement of the inhibitory effects. Furthermore, we were not able to demonstrate stimulation of starch digestion, a fact that may be revealing that net 

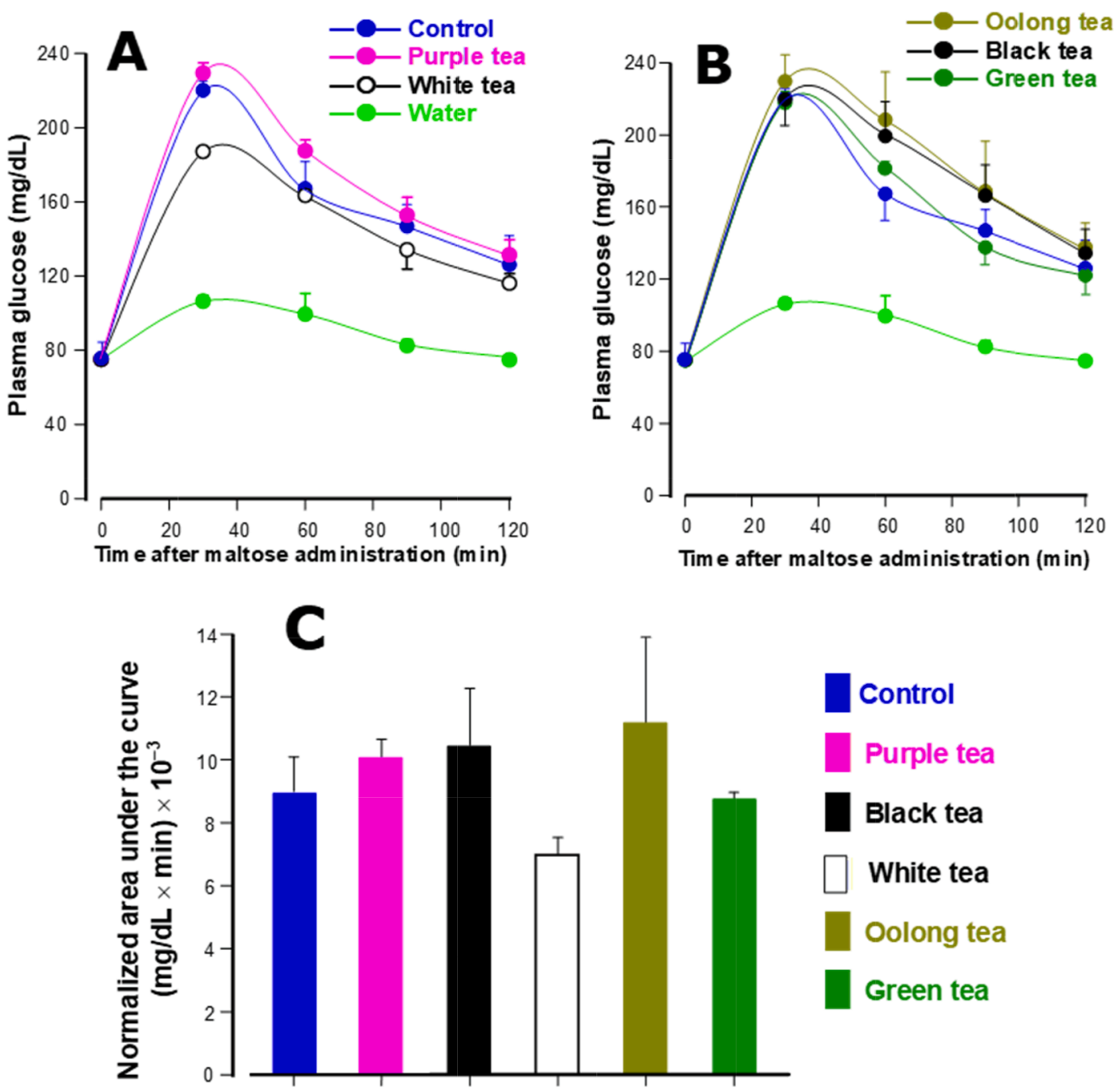

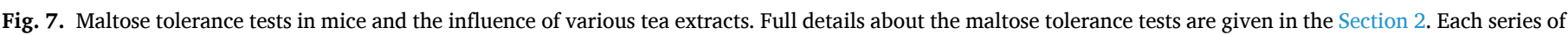

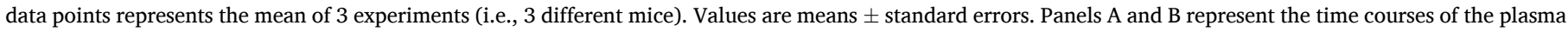

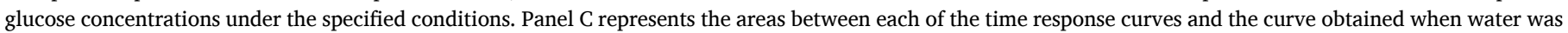
given to the mice. For each tea extract the administered dose was equal to $250 \mathrm{mg} / \mathrm{kg}$.

inhibition of $\alpha$-amylase is predominating in vivo. Another point is that the local concentrations of the inhibitors and the local concentrations of enzyme and substrate cannot be predicted, as the intestinal lumen is not homogeneous. This may also lead to different degrees of inhibition, especially if competition for the active site is significant. Transformation of the active principles may also occur in the intestinal lumen by virtue of the action of microorganisms (Correa et al., 2017), a phenomenon that can, in theory at least, generate more potent inhibitors than those originally present in the extract.

\subsection{On the significance of the computational simulations}

Implicit in the docking simulations was the idea that phenolic compounds are certainly involved because they are known inhibitors of $\alpha$-amylases at relatively low concentrations (10-50 $\mu \mathrm{M}$; Zhang et al., 2017; D'Costa \& Bordenave, 2021). Listed in Table 1 are those polyphenolic compounds that were effectively detected in the aqueous extracts used in the present study. Exhaustive hydroalcoholic extraction revealed an increased richness in compounds, at least for black and green tea, and probably also higher contents (Scoparo et al., 2012). However, the purpose of the present work was to investigate the action of extracts more closely resembling the daily brewed beverages. The computational investigation simulated a competitive inhibitory effect, where the phenolic compounds were docked to the active site of the enzyme. Although the results obtained with the docking simulations may suggest the compounds with the highest probability of binding to the $\alpha$-amylase active site, such compounds presented different ways of fitting (poses) with very close scores. This is due to the large number of rotatable bonds present in these molecules, what increases the degree of freedom of movement and generates different spatial conformations for the same molecule. Thus, the number of conformational species for the same molecule increases exponentially, what translates into interactions of different conformations of the same molecule with the active site of the enzyme. It should be remarked that since the simulations refer to binding to the active site, they necessarily refer solely to the phenomenon of inhibition. Stimulation could eventually be brought about by binding to other sites of the enzyme, a possibility that was not considered in the simulations.

\subsection{The molecular components involved in $\alpha$-amylase inhibition}

An important question that arises whenever the effects of complex extracts are investigated is one about the compounds that are responsible for the detected effects. This is a question that is actually connected to the topics that were discussed in the preceding sub-sections as it equally bears relation to the inhibitory action on the digestive enzymes. 

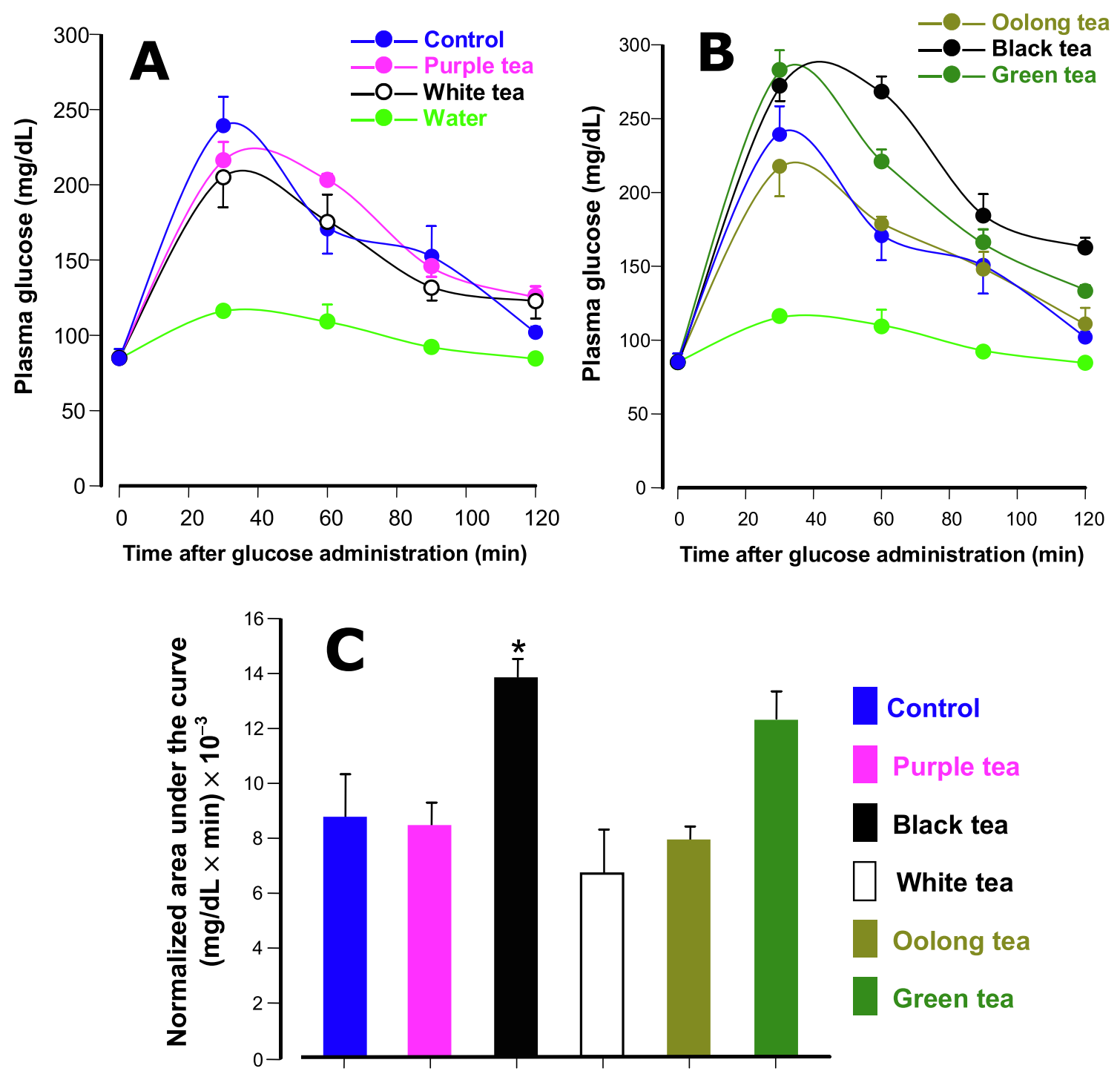

Fig. 8. Glucose tolerance tests in mice and the influence of various tea extracts. Full details about the glucose tolerance tests are given in the Section 2. Each series of data points represents the mean of 3 experiments (i.e., 3 different mice). Values are means \pm standard errors. Panels A and B represent the time courses of the plasma glucose concentrations under the specified conditions. Panel C represents the areas between each of the various time response curves and the curve obtained when water was given to the mice. For each tea extract the administered dose was equal to $250 \mathrm{mg} / \mathrm{kg}$. The asterisk in panel C (*) represents statistical significance at the $5 \%$ level relative to the control condition according to the Student-Newman-Keuls test.

The five extracts that were used at different concentrations certainly contain many different compounds and it is very difficult to define the exact compounds or group of compounds that are the main responsible for the effects. To this fact one has to add the observation that several tea extracts can also stimulate the $\alpha$-amylase, so that the effect on starch absorption that was observed in vivo could be the resultant of two antagonistic effects. There are no data available about the compounds that cause stimulation. But purple tea, besides being the strongest inhibitor of both $\alpha$-amylase and starch digestion, did not stimulate the enzyme and it should offer less difficulties to the attempt at identifying the main inhibitory molecular species based on the evidence produced in the present study. Purple tea is by far the richest one in anthocyanins (Kerio et al., 2012). Anthocyanins are in fact inhibitors of $\alpha$-amylases or $\alpha$-glucosidase, but their potency in vitro and in vivo is rather limited (Castilho et al., 2021; Wiese, Gärtner, Rawel, Winterhalter \& Kulling, 2009) and the purple tea extract content in these compounds is relatively small in absolute terms. Corroborating this, in the docking simulations, cyanidin-3-O-glucoside was classified as a relatively weak ligand. For all these reasons it is not very likely that the anthocyanins in the purple tea extract are the main inhibitors of $\alpha$-amylase unless phenomena like synergisms occur. On the other hand, epigallocatechin gallate is by far the most abundant polyphenolic in purple tea as well as in all other varieties investigated in the present work and it is well known that the compound inhibits $\alpha$-amylase (Desseaux et al., 2018). It is not the strongest inhibitor according to our docking simulations as it ranks 15, five places after the classical inhibitor acarbose. However, due to its abundance it is likely that it contributes significantly to the inhibitory activity of purple tea. Furthermore, purple tea contains several of the most effective inhibitors of $\alpha$-amylase according to our simulations which are the deoxyhexoside-hexoside-containing polyphenolics, especially the kaempferol and myricetin derivatives. Polysaccharides isolated from pu-erh tea, on the other hand, have also been demonstrated to inhibit the $\alpha$-amylase (Deng et al., 2015). The total polysaccharide content of the extract used in the present study is not very pronounced $(23 \mathrm{mg} / \mathrm{g})$. However, it is apparent that polysaccharides and eventually other macromolecules that can be precipitated by ethanol, contribute to the total inhibitory activity on the $\alpha$-amylase, even though the latter seems to be limited to $10 \%$ of the total inhibition. All these characteristics of the purple tea extract, combined with the absence of a significant stimulatory effect, are certainly 
contributing to the relatively strong inhibitory activity of this tea variety on both the $\alpha$-amylase and starch digestion.

A good contrast to purple tea is green tea, which was a weaker inhibitor of both $\alpha$-amylase and starch digestion in spite of its high content in epigallocatechin gallate. The inhibitory action of green tea seems to be strongly influenced by the opposing stimulatory effect which was present even when the second assay protocol (30 min of pre-incubation with the enzyme and reaction initiation by the addition of starch) was employed. The fact that the green tea extract contains more epigallocatechin gallate than the purple tea extract by a factor of 2.59 and that it is at the same time a weaker net inhibitor does not disprove the participation of this compound as an important inhibitor. It is much more likely that it represents a case in which the inhibitory activity is effectively counterbalanced by the stimulatory effect so that the net resulting effect is a diminished inhibitory activity.

Black tea seems to occupy an intermediate position between purple and green tea in terms of its inhibitory activity. It should be recalled that the black tea extract has the lowest content in phenolic compounds and that its content in epigallocatechin gallate was only $73 \%$ that of purple tea. It is perhaps significant, however, that no net stimulation of the $\alpha$-amylase by black tea was found. Furthermore, it is the only tea variety that contains theasinensin B (Tao et al., 2020), the compound that ranked in position 4 among the most likely to be bound by the $\alpha$-amylase (Fig. 3). Black tea, finally, is the tea type for which polysaccharides and eventually other macromolecules that can be precipitated by ethanol gave the most significant contribution to the $\alpha$-amylase inhibition (29\%). Remarkably, this occurs in spite of the fact that the content in polysaccharides of the extract used in the present work is relatively low when compared to white tea, for example. This suggests the existence of a highly specific structure in black tea, whose identification, however, needs a specific experimental design as it cannot be done with the data already available in the literature (Deng et al., 2015; Scoparo et al., 2016).

The behavior of oolong and white tea is more difficult to explain in terms of their molecular constituents. This is especially true for white tea which was the weakest inhibitor of the $\alpha$-amylase, but not necessarily the weakest inhibitor of starch digestion. Remarkably, the extracts of these two types of tea presented the highest contents in polysaccharides, but inhibition of the $\alpha$-amylase by these constituents was absent. Especially the behavior of the white tea extract within the general context of this work is a clear indication that our present knowledge about the molecular and mechanistic details of the effects of plant extracts on starch digestion is still largely incomplete. There can be many factors involved that escape to our present understanding as already mentioned above in the first part of the Discussion.

\section{Conclusion}

To our knowledge this study is the first attempt at comparing the effects of several Camellia sinensis varieties, extracted in the same way, on starch digestion in vivo and under identical conditions. Furthermore, the preparation procedure of the extracts was very close to that one used when teas are brewed for human consumption. The actions of the various tea extracts on glucose, maltose, and especially starch tolerance certainly present many complexities. Although the extracts of all tea varieties were able to inhibit starch digestion to a certain extent it is clear that the purple tea extract was the most effective inhibitor. For this variety epigallocatechin gallate can be devised as the main compound involved. The contributions of kaempferol and myricetin derivatives to the inhibition are also likely to be significant. For black tea epigallocatechin gallate seems also to be most active component. For the other varieties the identification of the compounds that are involved is obscured by the superposition of inhibitory and stimulatory effects. The bulk of the results obtained in the present study allow to formulate the hypothesis that in terms of a beneficial postprandial anti-hyperglycemic action in both healthy or diabetic individuals, the action of purple tea presents the best perspectives among all the varieties tested in the present study. Additional experimental work is required in order to clarify the exact role of the various molecular species that are involved in the inhibition of starch digestion.

\section{CRediT authorship contribution statement}

Tamires Barlati Vieira da Silva: Conceptualization, Methodology. Pâmela Alves Castilho: Conceptualization, Methodology. Anacharis Babeto de Sá-Nakanishi: Data curation, Writing - original draft. Flávio Augusto Vicente Seixas: Data curation, Writing - original draft, Software. Maria Inês Dias: Conceptualization, Methodology. Lillian Barros: Visualization, Investigation, Writing - review \& editing. Isabel C.F. R. Ferreira: Visualization, Investigation, Writing - review \& editing. Adelar Bracht: Supervision, Validation, Writing - review \& editing. Rosane Marina Peralta: Validation, Writing - review \& editing.

\section{Declaration of Competing Interest}

The authors declare that they have no known competing financial interests or personal relationships that could have appeared to influence the work reported in this paper.

\section{Acknowledgements}

This work was financially supported by grants from the Conselho Nacional de Desenvolvimento Científico e Tecnológico (CNPq-304090/ 2016-6), Coordenação do Aperfeiçoamento de Pessoal do Ensino Superior (CAPES) and Fundação Araucária (53/2019). The authors are grateful to the Foundation for Science and Technology (FCT, Portugal) for financial support through national funds FCT/MCTES to CIMO (UIDB/00690/2020) and through the institutional scientific employment program-contract for L. Barros and M.I. Dias contracts. This work was also funded by the European Regional Development Fund (ERDF) through the Regional Operational Program North 2020, within the scope

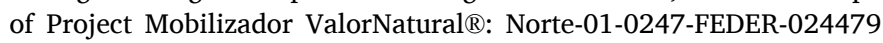
and GreenHealth: Norte-01-0145-FEDER-000042.

\section{Appendix A. Supplementary data}

Supplementary data to this article can be found online at https://doi. org/10.1016/j.foodres.2021.110781.

\section{References}

Adisakwattana, S., Yibchok-Anun, S., Charoenlertkul, P., \& Wongsasiripat, N. (2011). Cyanidin-3-rutinoside alleviates postprandial hyperglycemia and its synergism with acarbose by inhibition of intestinal $\alpha$-glucosidase. Journal of Clinical Biochemistry and Nutrition, 48(2), 154-160. https://doi.org/10.3164/jcbn.10-116

Awosika, T. O., \& Aluko, R. E. (2019). Inhibition of the in vitro activities of $\alpha$-amylase, $\alpha$-glucosidase and pancreatic lipase by yellow field pea (Pisum sativum L.) protein hydrolysates. International Journal of Food Science \& Technology, 54(6), 2021-2034. https://doi.org/10.1111/ijfs.14087

Bessada, S. M. F., Barreira, J. C. M., Barros, L., Ferreira, I. C. F. R., \& Oliveira, M. B. P. P. (2016). Phenolic profile and antioxidant activity of Coleostephus myconis (L.) Rchb. f.: An underexploited and highly disseminated species. Industrial Crops and Products, 89, 45-51. https://doi.org/10.1016/j.indcrop.2016.04.065

Castilho, P. A., Bracht, L., Barros, L., Albuquerque, B. R., Dias, M. I., Ferreira, I. C. F. R., ... Bracht, A. (2021). Effects of a Myrciaria jaboticaba peel extract on starch and triglyceride absorption and the role of cyanidin-3-O-glucoside. Food \& Function, 12 (6), 2644-2659. https://doi.org/10.1039/D0FO02927K

Correa, V. G., Gonçalves, G. A., de Sá-Nakanishi, A. B., Ferreira, I. C. F. R., Barros, L., Dias, M. I., ... Peralta, R. M. (2017). Effects of in vitro digestion and in vitro colonic fermentation on stability and functional properties of yerba mate (Ilex paraguariensis A. St. Hil.) beverages. Food Chemistry, 237, 453-460. https://doi.org/10.1016/j. foodchem.2017.05.125

D'Costa, A. S., \& Bordenave, N. (2021). Inhibition of starch digestion by flavonoids: Role of flavonoid-amylase binding kinetics. Food Chemistry, 341, 128256. https://doi.org/ 10.1016/j.foodchem.2020.128256

Deng, Y.-T., LinShiau, S.-Y., Shyur, L.-F., \& Lin, J.-K. (2015). Pu-erh tea polysaccharides decrease blood sugar by inhibition of alpha-glucosidase activity in vitro and in mice. Food \& Function, 6, 1539-1546. https://doi.org/10.1039/c4fo01025f 
Desseaux, V., Stocker, P., Brouant, P., \& Ajandouz, E. H. (2018). The mechanisms of alpha-amylase inhibition by flavan-3-ols and the possible impacts of drinking green tea on starch digestion. Journal of Food Science, 83(11), 2858-2865. https://doi.org/ 10.1111/1750-3841.14353

Dou, J., Lee, V. S. Y., Tzen, J. T. C., \& Lee, M.-R. (2007). Identification and comparison of phenolic compounds in the preparation of oolong tea manufactured by semifermentation and drying processes. Journal of Agricultural and Food Chemistry, 55 (18), 7462-7468.

Dubois, M., Gilles, K. A., Hamilton, J. K., Rebers, P. A., \& Smith, F. (1956). Colorimetric method for determination of sugars and related substances. Analytical Chemistry, 28 (3), 350-356. https://doi.org/10.1021/ac60111a017

Gao, J., Xu, P., Wang, Y., Wang, Y., \& Hochstetter, D. (2013). Combined effects of green tea extracts, green tea polyphenols or epigallocatechin gallate with acarbose on inhibition against $\alpha$-amylase and $\alpha$-glucosidase in vitro. Molecules, 18(9), 11614-11623. https://doi.org/10.3390/molecules180911614

Gutiérrez-Grijalva, E. P., Antunes-Ricardo, M., Acosta-Estrada, B. A., GutiérrezUribe, J. A., \& Basilio Heredia, J. (2019). Cellular antioxidant activity and in vitro inhibition of $\alpha$-glucosidase, $\alpha$-amylase and pancreatic lipase of oregano polyphenols under simulated gastrointestinal digestion. Food Research International, 116, 676-686. https://doi.org/10.1016/j.foodres.2018.08.096

Jones, G., Willett, P., Glen, R. C., Leach, A. R., \& Taylor, R. (1997). Development and validation of a genetic algorithm for flexible docking. Journal of Molecular Biology, 267, 727-748. https://doi.org/10.4000/formationemploi.3853

Kato-schwartz, C. G., Bracht, F., Almeida, G. D., Assunção, A., Francielli, T., Brugnari, T., .. Peralta, R. M. (2018). Inhibition of $\alpha$-amylases by pentagalloyl glucose : Kinetics, molecular dynamics and consequences for starch absorption. Journal of Functional Foods, 44, 265-273. https://doi.org/10.1016/j.jff.2018.03.025

Kato-Schwartz, C. G., Corrêa, R. C. G., de Souza Lima, D., de Sá-Nakanishi, A. B., de Almeida Gonçalves, G., Seixas, F. A. V., ... Peralta, R. M. (2020). Potential antidiabetic properties of Merlot grape pomace extract: An in vitro, in silico and in vivo study of $\alpha$-amylase and $\alpha$-glucosidase inhibition. Food Research International, 137, 109462. https://doi.org/10.1016/j.foodres.2020.109462

Kato, C. G., Gonçalves, G.d. A., Peralta, R. A., Seixas, F. A. V., de Sá-Nakanishi, A. B., Bracht, L., ... Peralta, R. M. (2017). Inhibition of $\alpha$-amylases by condensed and hydrolysable tannins: Focus on kinetics and hypoglycemic actions. Enzyme Research, 2017, 1-12. https://doi.org/10.1155/2017/5724902

Kerio, L. C., Wachira, F. N., Wanyoko, J. K., \& Rotich, M. K. (2012). Characterization of anthocyanins in Kenyan teas: Extraction and identification. Food Chemistry, 131(1), 31-38. https://doi.org/10.1016/j.foodchem.2011.08.005

Kilel, C., Faranj, A. K., Wanyoko, J. K., Wachira, N., \& Mwingirwa, V. (2013). Green tea from purple leaf coloured tea clones in Kenya - their quality characteristics. Food Chemistry, 141(2), 769-775. https://doi.org/10.1016/j.foodchem.2013.03.051

Kim, S., Thiessen, P. A., Bolton, E. E., Chen, J., Fu, G., Gindulyte, A., ... Bryant, S. H. (2016). PubChem Substance and Compound databases. Nucleic Acids Research, 44 (D1), D1202-D1213. https://doi.org/10.1093/nar/gkv951

Kim, Y., Goodner, K. L., Park, J.-D., Choi, J., \& Talcott, S. T. (2011). Changes in antioxidant phytochemicals and volatile composition of Camellia sinensis by oxidation during tea fermentation. Food Chemistry, 129(4), 1331-1342.

Kong, J. M., Chia, L. S., Goh, N. K., Chia, T. F., \& Brouillard, R. (2003). Analysis and biological activities of anthocyanins. Phytochemistry, 64(5), 923-933. https://doi org/10.1016/S0031-9422(03)00438-2

Lai, Y.-S., Li, S., Tang, Q., Li, H.-X., Chen, S.-X., Li, P.-W., ... Guo, X. (2016). The DarkPurple Tea Cultivar "Ziyan" Accumulates a Large Amount of Delphinidin-Related Anthocyanins. Journal of Agricultural and Food Chemistry, 64(13), 2719-2726. https://doi.org/10.1021/acs.jafc.5b0403610.1021/acs.jafc.5b04036.s001

Lee, J., Durst, R. W., Wrolstad, R. E., Eisele, T., Giusti, M. M., Haché, J., Wightman, J. D. (2005). Determination of total monomeric anthocyanin pigment content of fruit juices, beverages, natural colorants, and wines by the $\mathrm{pH}$ differential method: Collaborative study. Journal of AOAC International, 88(5), 1269-1278. https://doi.org/10.1093/jaoac/88.5.1269

Lochocka, K., Bajerska, J., Glapa, A., Fidler-Witon, E., Nowak, J. K., Szczapa, T., ... Walkowiak, J. (2015). Green tea extract decreases starch digestion and absorption from a test meal in humans: A randomized, placebo-controlled crossover study. Scientific Reports, 5(1). https://doi.org/10.1038/srep12015

Miao, M., Jiang, B., Jiang, H., Zhang, T., \& Li, X. (2015). Interaction mechanism between green tea extract and human a -amylase for reducing starch digestion. Food Chemistry, 186, 20-25. https://doi.org/10.1016/j.foodchem.2015.02.049

Miller, G. L. (1959). Use of dinitrosalicylic acid reagent for determination of reducing sugar. Analytical Chemistry, 31(3), 426-428. https://doi.org/10.1021/ac60147a030
Morris, G. M., Huey, R., Lindstrom, W., Sanner, M. F., Belew, R. K., Goodsell, D. S., \& Olson, A. J. (2009). AutoDock4 and AutoDockTools4: Automated docking with selective receptor flexibility. Journal of Computational Chemistry, 30(16), 2785-2791. https://doi.org/10.1002/jcc.v30:1610.1002/jcc.21256

Nyambe-Silavwe, H., Villa-Rodriguez, J. A., Ifie, I., Holmes, M., Aydin, E., Jensen, J. M., \& Williamson, G. (2015). Inhibition of human $\alpha$-amylase by dietary polyphenols. Journal of Functional Foods, 19, 723-732. https://doi.org/10.1016/j.jff.2015.10.003

Rocha, D. M. U. P., Caldas, A. P. S., da Silva, B. P., Hermsdorff, H. H. M., \& Alfenas, R. de C. G. (2019). Effects of blueberry and cranberry consumption on type 2 diabetes glycemic control: A systematic review. Critical Reviews in Food Science and Nutrition, 59(11), 1816-1828. https://doi.org/10.1080/10408398.2018.1430019.

Saeedi, P., Petersohn, I., Salpea, P., Malanda, B., Karuranga, S., Unwin, N., Colagiuri, S., Guariguata, L., Motala, A. A., Ogurtsova, K., Shaw, J. E., Bright, D., \& Williams, R. (2019). Global and regional diabetes prevalence estimates for 2019 and projections for 2030 and 2045: Results from the International Diabetes Federation Diabetes Atlas, $9^{\text {th }}$ edition. Diabetes Research and Clinical Practice, 157, 107843. https://doi. org/10.1016/j.diabres.2019.107843.

Scoparo, C. T., de Souza, L. M., Dartora, N., Sassaki, G. L., Gorin, P. A. J., \& Iacomini, M. (2012). Analysis of Camellia sinensis green and black teas via ultra high performance liquid chromatography assisted by liquid-liquid partition and two-dimensional liquid chromatography (size exclusion $\times$ reversed phase). Journal of Chromatography A, 1222, 29-37.

Scoparo, C. T., Souza, L. M., Dartora, N., Sassaki, G. L., Santana-Filho, A. P., Werner, M. F. P., ... Iacomini, M. (2016). Chemical characterization of heteropolysaccharides from green and black teas (Camellia sinensis) and their antiulcer effect. International Journal of Biological Macromolecules, 86, 772-781. https:// doi.org/10.1016/j.ijbiomac.2016.02.017

Santos, K. B., Guedes, I. A., Karl, A. L. M., \& Dardenne, L. E. (2020). Highly flexible ligand docking: Benchmarking of the DockThor Program on the LEADS-PEP ProteinPeptide Data Set. Journal of Chemical Information and Modeling, 60(2), 667-683. https://doi.org/10.1021/acs.jcim.9b0090510.1021/acs.jcim.9b00905.s001

da Silva, S. M., Koehnlein, E. A., Bracht, A., Castoldi, R., de Morais, G. R., Baesso, M. L., ... Peralta, R. M. (2014). Inhibition of salivary and pancreatic $\alpha$-amylases by a pinhão coat (Araucaria angustifolia) extract rich in condensed tannin. Food Research International, 56, 1-8. https://doi.org/10.1016/j.foodres.2013.12.004

Tao, S., Chen, G., Xu, W., Peng, Y., Wan, P., Sun, Y., ... Liu, Z. (2020). Preparation of theasinensin A and theasinensin B and exploration of their inhibitory mechanism on $\alpha$-glucosidase. Food \& Function, 11(4), 3527-3538. https://doi.org/10.1039/ C9FO03054A

Thomsen, R., \& Christensen, M. H. (2006). MolDock: A New Technique for HighAccuracy Molecular Docking. Journal of Medicinal Chemistry, 49(11), 3315-3321. https://doi.org/10.1021/jm051197e

Thorsen, K., Drengstig, T., \& Ruoff, P. (2014). Transepithelial glucose transport and Na + /K + homeostasis in enterocytes: An integrative model. American Journal of Physiology-Cell Physiology, 307(4), C320-C337. https://doi.org/10.1152/ ajpcell.00068.2013

Wasana, K. G. P., Attanayake, A. P., Weerarathna, T. P., \& Jayatilaka, K. A. P. W. (2021). Efficacy and safety of a herbal drug of Coccinia grandis (Linn.) Voigt in patients with type 2 diabetes mellitus: A double blind randomized placebo controlled clinical trial. Phytomedicine, 81, 153431. https://doi.org/10.1016/j.phymed.2020.153431

Wiese, S., Gärtner, S., Rawel, H. M., Winterhalter, P., \& Kulling, S. E. (2009). Protein interactions with cyanidin-3-glucoside and its influence on $\alpha$-amylase activity. Journal of the Science of Food and Agriculture, 89(1), 33-40. https://doi.org/10.1002/ jsfa.v89:110.1002/jsfa.3407

Yang, C.-Y., Yen, Y.-Y., Hung, K.-C., Hsu, S.-W., Lan, S.-J., \& Lin, H.-C. (2019). Inhibitory effects of pu-erh tea on alpha glucosidase and alpha amylase: A systemic review. Nutrition \& Diabetes, 9(1), 23. https://doi.org/10.1038/s41387-019-0092-y

Yang, X., \& Kong, F. (2016). Effects of tea polyphenols and different teas on pancreatic $\alpha$-amylase activity in vitro. LWT - Food Science and Technology, 66, 232-238. https:// doi.org/10.1016/j.lwt.2015.10.035

Zhang, B. W., Li, X., Sun, W. L., Xing, Y., Xiu, Z. L., Zhuang, C. L., \& Dong, Y. S. (2017). Dietary flavonoids and acarbose synergistically inhibit $\alpha$-glucosidase and lower postprandial blood glucose. Journal of Agricultural and Food Chemistry, 65(38), 8319-8330. https://doi.org/10.1021/acs.jafc.7b02531

Zielinski, A. A. F., Haminiuk, C. W. I., \& Beta, T. (2016). Multi-response optimization of phenolic antioxidants from white tea (Camellia sinensis L. Kuntze) and their identification by LC-DAD-Q-TOF-MS/MS. LWT-Food Science and Technology, 65, 897-907. 